\title{
Arc Jet Testing of CMC Samples with Transpiration Cooling
}

\author{
Thomas Reimer ${ }^{1}$ \\ DLR, German Aerospace Center, Pfaffenwaldring 38-40, 70569 Stuttgart, Germany \\ Burkard Esser ${ }^{2}$, Ali Gülhan ${ }^{3}$ \\ DLR, German Aerospace Center, Linder Höhe, 51147 Cologne, Germany
}

High speed sustained atmospheric flight creates high thermal loads at the tip, leading edges, intake ramps or engine structures of a flight vehicle. However, sharp edges are mandatory for these vehicles in order to obtain the required aerodynamic performance. To provide technical solutions for these problems, the concept of using porous ceramic matrix composite (CMC) materials in combination with active cooling by transpiration was investigated. An arc jet test campaign was carried out to determine basic parameters in terms of minimum required coolant focusing on liquid water as the coolant media. The tests were stagnation tests on flat samples with a diameter of 50 mm. The front wall thickness was $8 \mathrm{~mm}$. The tests were carried out in the L3K and L2K arc jet facilities of DLR Cologne at approximately $1 \mathrm{MW} / \mathrm{m}^{2}$ heat load. Good results were achieved in terms of mass flow data for $\mathrm{C} / \mathrm{C}$ samples. A number of tests could be carried out at low supply pressures and low mass flow. A medium value of the lower limit mass flow is $0.33 \mathrm{~g} / \mathrm{s}$ at a pressure of $225 \mathrm{hPa}$ which is equal to $0.152 \mathrm{~kg} / \mathrm{m}^{2} \mathrm{~s}$. With aluminum oxide samples, a cold surface could also be maintained, however, it was not possible to establish a steady-state condition in terms of mass flow and supply pressure.

$\begin{array}{ll} & \text { Nomenclature } \\ \dot{q}_{c w} & =\text { heat flux density on cold wall, } \mathrm{W} / \mathrm{m}^{2} \\ \dot{q}_{h w} & =\text { heat flux density on hot wall, } \mathrm{W} / \mathrm{m}^{2} \\ a & =\text { factor }, \\ k_{d} & =\text { Darcy coefficient, } \mathrm{m}^{2} \\ k_{f} & =\text { Forchheimer coefficient, } \mathrm{m} \\ R_{N} & =\text { nose radius, } \mathrm{m} \\ \rho_{\infty} & =\text { atmospheric density at flight altitude, } \mathrm{kg} / \mathrm{m}^{3} \\ \rho_{S L} & =\text { atmospheric density at sea level, } \mathrm{kg} / \mathrm{m}^{3} \\ U_{\infty} & =\text { velocity at flight altitude, } \mathrm{m} / \mathrm{s} \\ U_{C O} & =\text { velocity in circular orbit, } \mathrm{m} / \mathrm{s} \\ h_{s t} & =\text { stagnation enthalpy, } \mathrm{J} / \mathrm{kg} \\ c_{p, a i r} & =\text { heat capacity of air, } \mathrm{J} / \mathrm{kgK} \text { ) } \\ T_{h w} & =\text { temperature of hot wall, } \mathrm{K} \\ T_{c w} & =\text { temperature of cold wall, } \mathrm{K}\end{array}$

\section{Introduction}

big challenge in current high-speed flight research is the topic of sustained hypersonic flight in
experiencing considerable thermal loads on the surface. Typically, the critical areas of the vehicle are the nose
and the wing leading edges, as well as the fin edges. In addition, such vehicles are usually conceived to have
airbreathing propulsion system to take advantage of the presence of atmospheric oxygen which means in turn that
there are additional critical elements on the vehicle surface like the engine inlet.

${ }^{1}$ Research Engineer, Institute of Structures and Design
${ }^{2}$ Research Engineer, Institute of Aerodynamics and Flow Technology, Supersonic and Hypersonic Technologies
${ }^{3}$ Department Head, Institute of Aerodynamics and Flow Technology, Supersonic and Hypersonic Technologies 
The need for an aerodynamically efficient design results in these vehicles to be designed very slender with sharp leading edges on the nose, wings and engine intakes in order to minimize drag. The result is high thermal loads on these elements as the heat load in hypersonic flow depends on the curvature radius of the structure in the flow in that way that sharp edges with a small curvature radius will experience a higher thermal load than blunt shapes with a large curvature radius. A good engineering relation of this phenomenon was developed by Detra, Kemp and Riddell ${ }^{1}$, giving the cold-wall heat flux density in the stagnation point of a sphere in dependence of the flight conditions and the radius of that sphere. It was developed for calculations of re-entry conditions from a circular orbit.

$$
\dot{q}_{c w}=\frac{a}{\sqrt{R_{N}}}\left[\frac{\rho_{\infty}}{\rho_{S L}}\right]^{0.5}\left[\frac{U_{\infty}}{U_{C O}}\right]^{3.15}
$$

This relation can be extended to give the heating rate on a hot wall, employing an enthalpy ratio

$$
\dot{q}_{h w}=\dot{q}_{c w}\left[\frac{h_{s t}-c_{p, a i r} T_{h w}}{h_{s t}-c_{p, a i r} T_{c w}}\right]
$$

The TPS of a hypersonic flight vehicle that is supposed to fly for an extended time and possibly even multiple times without major refurbishment has to be reusable. State-of-the-art reusable TPS, like that of the Space Shuttle, are limited to use temperatures of around $1600^{\circ} \mathrm{C}$ as the result of a heat flux of around $600 \mathrm{~kW} / \mathrm{m}^{2}$ when radiation adiabatic conditions are assumed. However, the nose radius of the Shuttle is large compared to the envisioned systems for future hypersonic vehicles.

There are new developments for advanced TPS designs based on CMC materials with higher application temperatures in the range of $1700-1800^{\circ} \mathrm{C}$. For instance DLR developed the C/C-SiC nose for the re-usable X-38 re-entry vehicle ${ }^{2}$ but also for single-flight items like ballistic capsules like EXPRESS ${ }^{3}$ and EXPERT ${ }^{4}$. In contrast to these blunt shaped vehicles, current work at DLR is focused on facetted shapes with sharp edges in the SHEFEX project with the flights of SHEFEX I and SHEFEX II $^{5}$ already performed and the continuation with SHEFEX III.

One more concept that is investigated and also requiring fairly sharp leading edges is the SpaceLiner ${ }^{6}$. It is a generic vehicle concept that is supposed to make long-range passenger flights on a sub-orbital trajectory between e.g. Europe and Australia. It requires highly efficient aerodynamics and thus features a slender fuselage with thin wing profiles and leading edges with a small curvature radius.

When the heat flux on the leading edge of the SpaceLiner is calculated with flight data at Mach 8 at an altitude of $37 \mathrm{~km}$ and assuming a curvature radius of relevant size as shown in Fig. 1, it becomes evident that a temperature of $1600^{\circ} \mathrm{C}$ can be surpassed and the need for an improved TPS arises. In this respect it is interesting to consider that the leading edge curvature radius of the X-43 was 0.03 in which is $0.762 \mathrm{~mm}$ !

Adopting an ablative TPS may be a short-term solution for experimental systems, but not for long-term developments because the ablative heat shield is changing the surface geometry and thus the aerodynamics of the vehicle which leads to performance loss.

Another material option to cope with the challenges of sustained hypersonic flight could be Ultra-HighTemperature Ceramics (UHTC). These are ceramic compounds fabricated from rare earths with a high melting point like typically Zirconia, Hafnium or Boron with additions of other elements like carbides from Silicon. But also these types of ceramics suffer from degradation effects like oxidation at high temperature and still need to be improved until they may be used to produce the kind of structures required on hypersonic vehicles ${ }^{7}$.

The focus in this work is on active cooling techniques employing ceramics as the structural material. The developments use porous CMC materials to design a transpiration cooling system which feeds a certain amount of coolant through the wall of the structure in order to keep it at an acceptable temperature. Transpiration cooling as a special case of active cooling is not new, it has been followed for a long time, however, earlier investigations mainly concentrated on porous metals which tend to fail if local hot spots and hence melting occurs. 


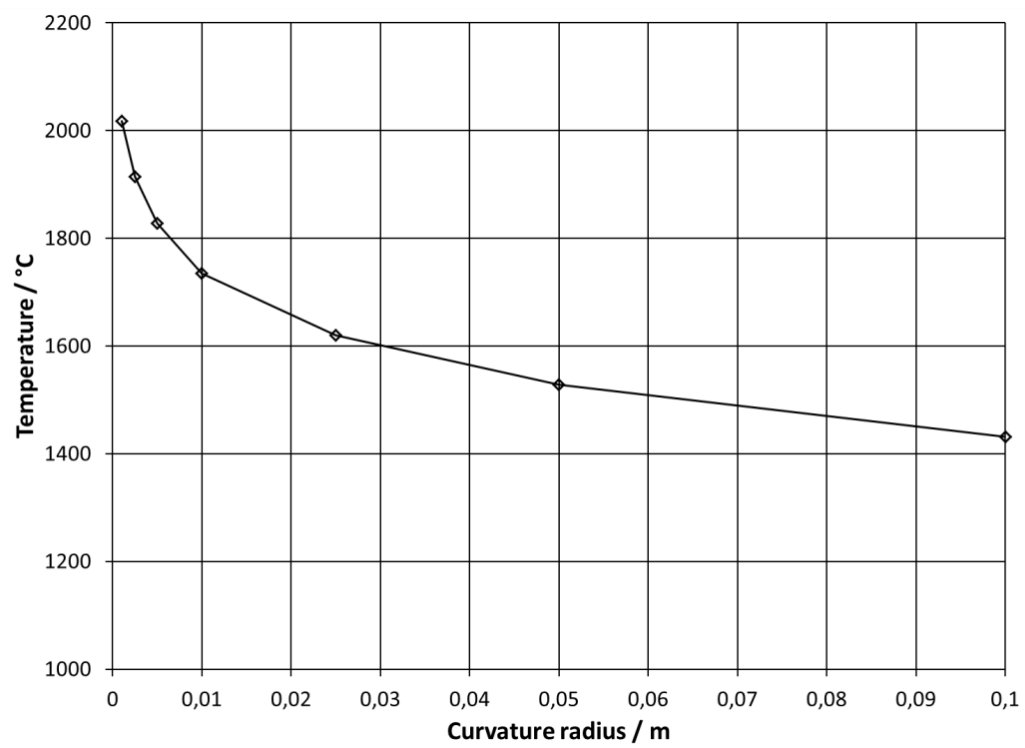

Figure 1. SpaceLiner leading edge temperature at Mach 8 at $37 \mathrm{~km}$ altitude depending on the leading edge curvature radius assuming hot wall radiation adiabatic conditions and unswept wing.

The technology of active transpiration cooling shall now be adapted to be applied to critical elements of hypersonic vehicles For the investigations presented here, the coolant was water. Water as a coolant for transpiration cooling in a hypersonic flow regime showed promising results in earlier tests ${ }^{8}$.

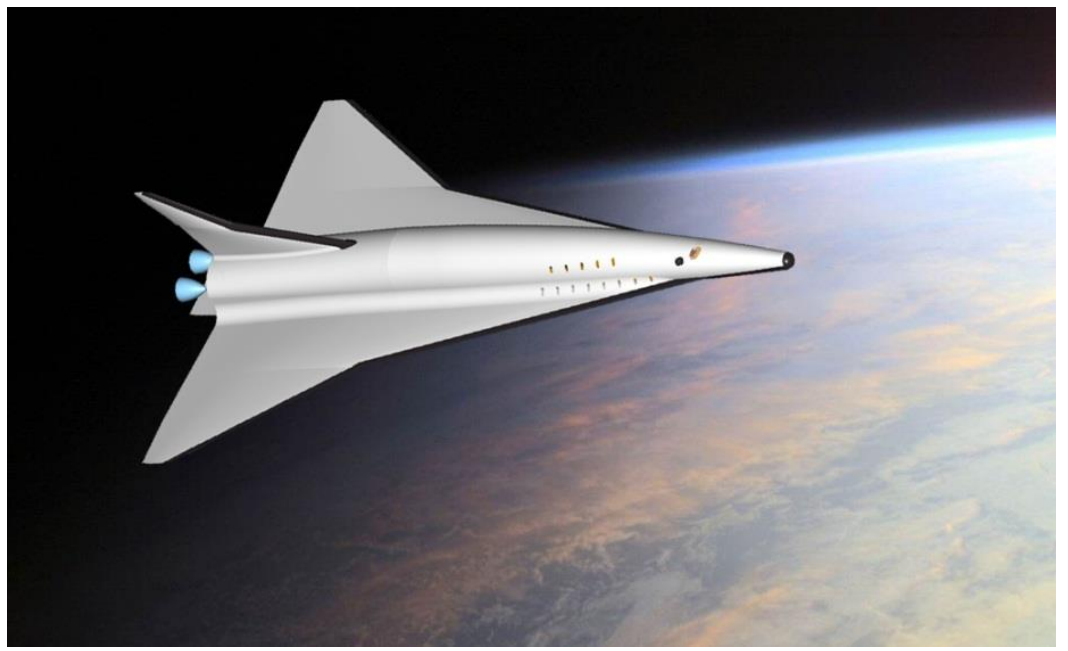

Figure 2. Artist's view of the SpaceLiner passenger stage.

A test program was carried out that investigates the technological basics required for active cooling of critical elements of hypersonic vehicles. The activities were carried out in the framework of the FAST20XX project funded by the European Union. The project acronym is derived from the full title "Future high-Altitude high-Speed Transport 20XX". It aims at providing a technological foundation for the introduction of advanced high-altitude high-speed transportation in the medium to long term by defining the most critical research, technology and development building blocks.

Based on the experience with transpiration cooling already made earlier ${ }^{9,10}$ a test program was defined for DLR's arc-heated facilities LBK in Cologne. In its first step the program concentrated on the testing of flat-faced cylinder shaped samples as shown in Fig. 3. 


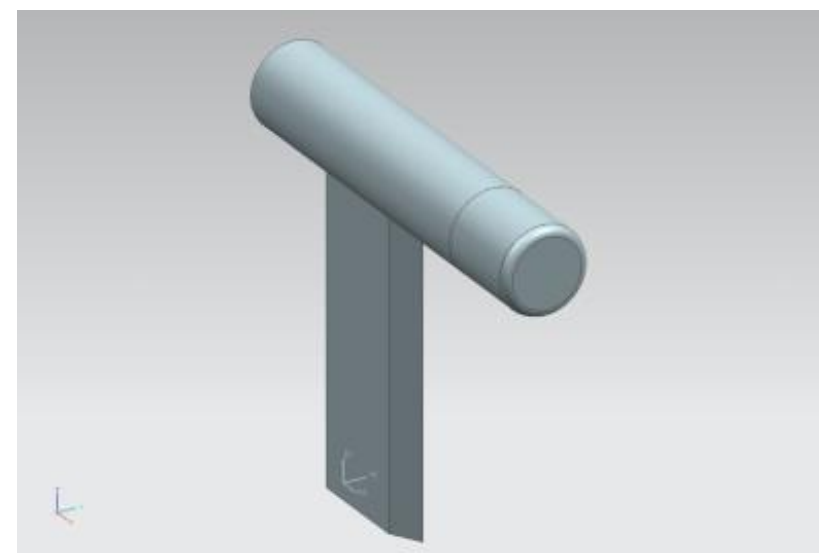

Figure 3. Stagnation test configuration.

This configuration was used for a screening of different materials. The samples were tested in stagnation point configuration with the flat face oriented normal to the flow direction. The main test parameters are listed in Table 1. With the tests the cooling effectiveness of the materials should be determined by varying the coolant mass flow via the supply pressure.

Table 1. Screening test parameters.

\begin{tabular}{|l|l|}
\hline & Screening Test Campaign \\
\hline Materials & C/C \\
& C/C-SiC \\
& Al-Ox-fibre CMC \\
\hline Coolant & Water \\
& Nitrogen gas \\
\hline Heat Load & $1 \mathrm{MW} / \mathrm{m}^{2}$ cold wall HF \\
\hline Pressure & Test stagnation pressure $\sim 40 \mathrm{hPa}$ \\
\hline
\end{tabular}

One of the standard test setups for the LBK facility in Cologne supports samples with a diameter of $50 \mathrm{~mm}$. This size was selected for the screening tests. A sketch of the final test setup is shown in Fig. 4. Its main components are the sample and a metallic adapter to the modell support system that allows a lead through of the instrumentation and enables coolant supply to the sample. The space between sample and adapter is used as a coolant reservoir. Seals are placed at the interfaces to prevent lateral coolant outflow.

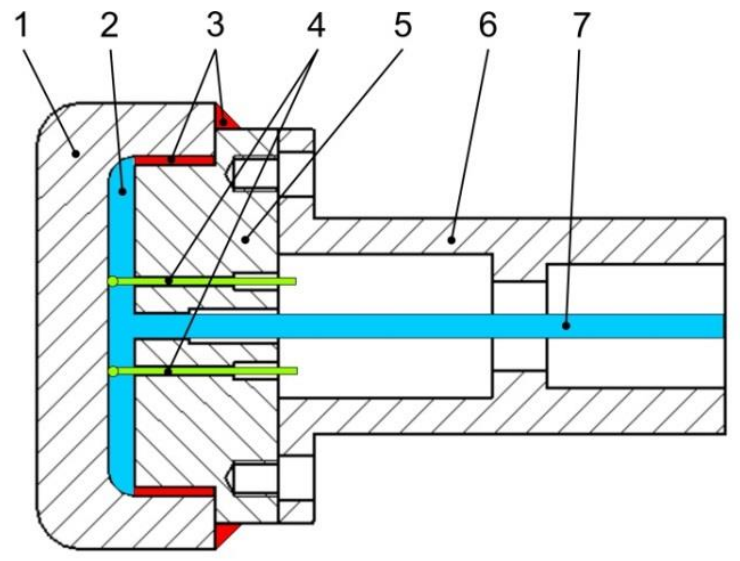

1 Sample

2 Water reservoir

3 Seal / adhesive

4 Thermocouples

5 Metallic holder

6 Adapter to facility

7 Water supply

Figure 4. Sketch of the sample assembly. 


\section{Materials and Samples}

The tests were carried out with three types of materials listed in Table 1 with varying fibre orientations. That is due to the fact that the properties of the materials are anisotropic also with regard to the permeability which is the key issue for the operational parameters of transpiration cooled structures. The materials are produced in the form of plates via the layup and subsequent processing of fiber textiles with a $0^{\circ} / 90^{\circ}$ weave.

In the case of the $\mathrm{C} / \mathrm{C}$ and the $\mathrm{C} / \mathrm{C}-\mathrm{SiC}$ material the processing starts out with the same CFRP production. Carbon fiber textiles are impregnated with a phenolic resin in an autoclave process. After the curing the plates are given into a carbonization or pyrolysis process. At temperatures up to $1600^{\circ} \mathrm{C}$ the phenolic matrix is converted into amorphous carbon. In the case of $\mathrm{C} / \mathrm{C}$, the process stops and samples are manufactured. To arrive at the $\mathrm{C} / \mathrm{C}-\mathrm{SiC}$ material, the $\mathrm{C} / \mathrm{C}$ plates are infiltrated with silicon via a melt infiltration process during which the amorphous carbon as the remainder of the matrix and to some extent the fibers react with the liquid silicon to form $\mathrm{SiC}$ as the new matrix. Since the porosity of the resulting material is very low, advantage is taken from the effect that a certain percentage of the matrix volume is occupied by free silicon that did not convert. When the C/C-SiC is heated up in another processing step without offering additional silicon, the free silicon can be liquefied again and drawn out of the material, thus raising the porosity a little bit which enhances the permeability and should be beneficial for the cooling effect.

Samples with various fibre orientations were tested. An overview of the fibre orientations for the different materials is given in Table 2 .

Table 2. Sample materials.

\begin{tabular}{|l|l|}
\hline Material & $\begin{array}{c}\text { Fibre orientation relative to } \\
\text { coolant flow direction }\end{array}$ \\
\hline Carbon / Carbon $(\mathrm{C} / \mathrm{C})$ & $\begin{array}{l}\text { Perpendicular } \\
\text { Parallel }\end{array}$ \\
\hline Carbon / Carbon - Silicon Carbide $(\mathrm{C} / \mathrm{C}-\mathrm{SiC})$ & Perpendicular \\
& Parallel \\
\hline Oxide fiber CMC & Parallel \\
\hline
\end{tabular}

\section{Pre-Tests}

For the CMC sample materials applied, the corresponding Darcian and Forchheimer permeabilities were determined for standardized sample geometries and by means of a static approach, see Ref. 11 for example. Those gas permeability coefficients enable the prediction of pressure losses at specific operating conditions and with different coolants. The determination of those coefficients was performed under much higher pressures and mass flow rates as for envisaged arc-jet tests, so all occurring coolant flow conditions will be surely covered. In addition, before going into arc-jet testing, the model set-up was tested for leakage and for determining the ultimate strength of the adhesive joints between holder and sample. The recorded mass flow rates in the pre-tests up to 1 atm differential pressure were in the range of $0-0.5 \mathrm{~g} / \mathrm{sec}$ of water.

The permeability properties of the material were determined and the relevant Darcy and Forchheimer coefficients were measured with results for $\mathrm{C} / \mathrm{C}$ given in Table 3.

Table 3. Permeability coefficients.

\begin{tabular}{|c|c|c|c|}
\hline Sample & $\begin{array}{c}\mathbf{k}_{\mathbf{D}} \\
{\left[\mathbf{m}^{2}\right]}\end{array}$ & $\begin{array}{c}\mathbf{k}_{\mathbf{F}} \\
{[\mathbf{m}]}\end{array}$ & $\begin{array}{c}\Delta \mathbf{p}_{\text {max }} \\
{[\mathbf{b a r}]}\end{array}$ \\
\hline PH2046-k-mean & $1.08 \mathrm{E}-13$ & $8.07 \mathrm{E}-9$ & $10.1-11.2$ \\
\hline PH2046-g-1 & $1.16 \mathrm{E}-13 \pm 1.20 \%$ & $7.95 \mathrm{E}-9 \pm 3.68 \%$ & 4.0 \\
\hline
\end{tabular}




\section{Arc Jet Testing}

The screening tests were performed in the arc-heated facilities LBK which are located at DLR's research centre in Cologne. LBK consists of two test legs L2K and L3K, both of them were used. A schematic diagram of the facilities is shown in Fig. 5.

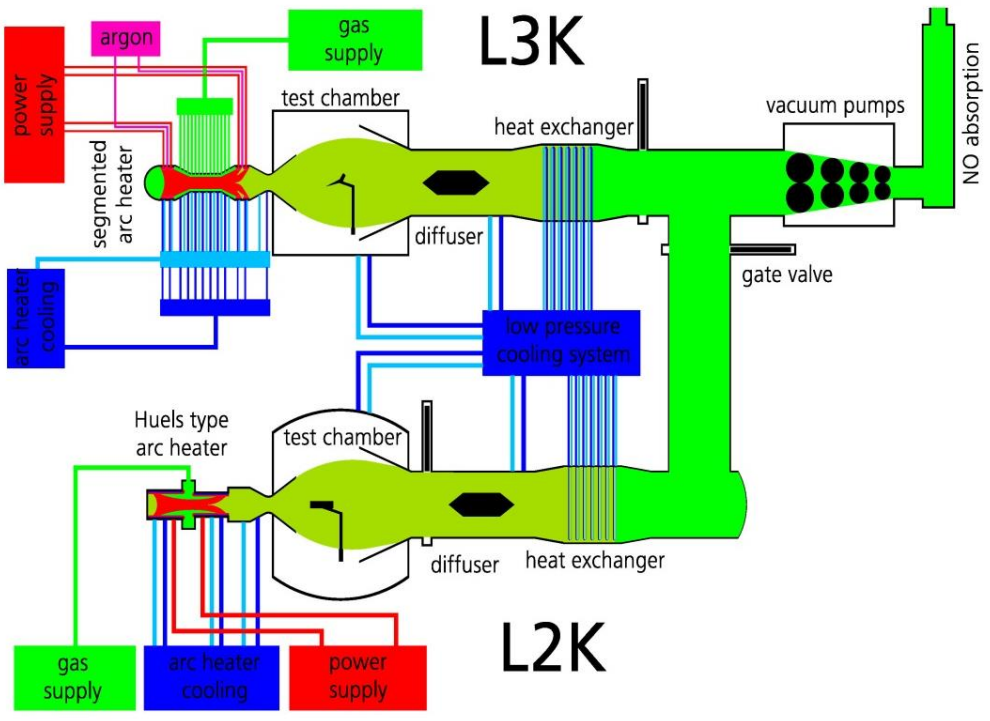

Figure 5. Sketch of the LBK facilities.

Central part of each facility is the arc-heater which is used to transfer the working gas to a high enthalpy state. L3K is equipped with a $6 \mathrm{MW}$ segmented arc heater, while L2K is using a Huels-type arc heater with a power of 1.4 MW. From the reservoir at the downstream end of the arc heater the working gas is accelerated gas to hypersonic velocities by a convergent-divergent nozzle. After passing the nozzle exit the accelerated gas enters the test chamber where it forms a free jet. A more detailed description of the facility can be found in $^{12,13}$.

Due to the nozzle's modular design throat and exit diameters are variable and can be adapted to testing requirements. The half angle of the expansion part is $12^{\circ}$. Depending on the nozzle's exit diameter Mach numbers in the range from 3 to 10 can be achieved at stagnation pressures up to $1300 \mathrm{hPa}$. For the transpiration cooling test campaign a nozzle with a throat diameter of $29 \mathrm{~mm}$ was used. In Fig. 6 the schematic of the water supply is shown together with the installation of the pump in order to adjust the desired pressure difference between sample surface and the reservoir pressure on the inside of the sample.

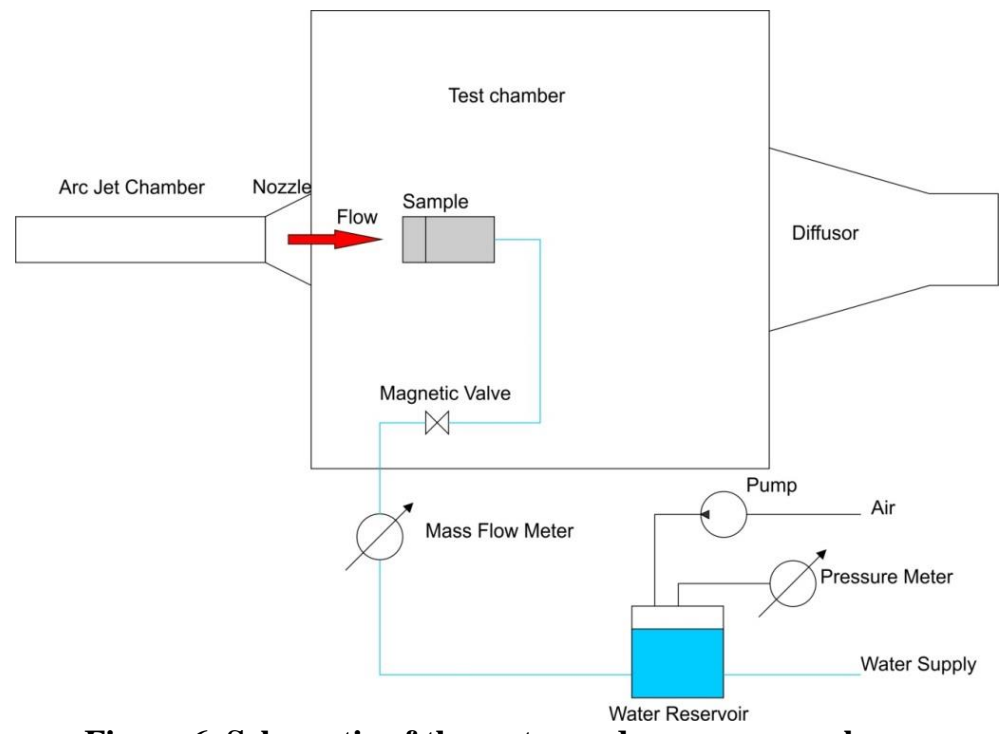

Figure 6. Schematic of the water and pressure supply.

American Institute of Aeronautics and Astronautics 
Figure 7 shows a photograph of the assembled sample setup. Up to three thermocouples were placed in the interior to measure the sample's backside temperature and the temperature in the coolant reservoir. The surface temperature of the samples was measured with two pyrometers and an infrared camera system. In addition to the temperature measurements the coolant mass flow rate and its supply pressure were continuously measured.

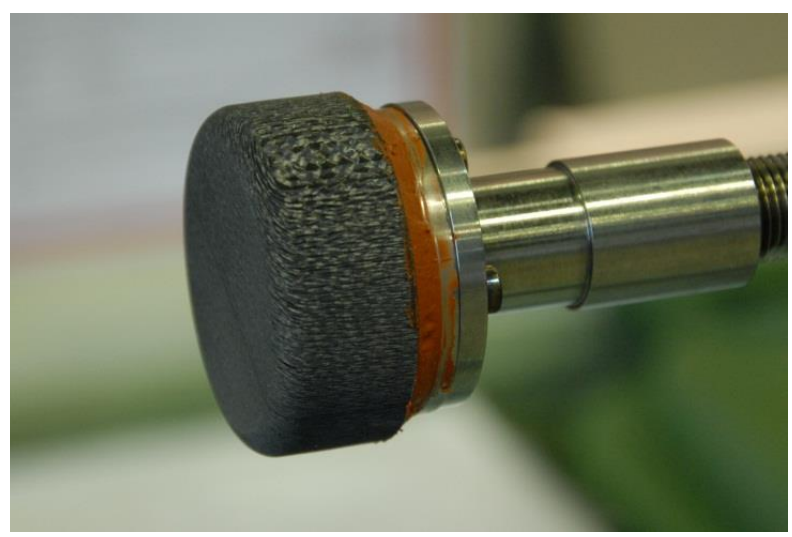

Figure 7. Photograph of the test setup.

Several tests were required to find a reliable and repeatable test procedure. During the startup phase of the facility the sample was placed outside of the flow field in the background of the test chamber where the static pressure is below $1 \mathrm{hPa}$. Due to the low pressure a specific startup procedure has to be applied when using water as coolant, since the sample's ambient pressure was below the pressure of the triple point. Therefore, the coolant reservoir had to be kept empty during facility startup to avoid ice formation in the reservoir causing a blockage of coolant flow. A valve was installed in the coolant supply line which was opened only a few seconds before moving the sample into the flow.

\section{A. C/C Samples with Parallel Fiber Orientation}

Table 3 gives an overview about the tests carried out with samples that have the fibers in parallel to the flow direction.

Table 4. Samples tested with fibers parallel to the flow direction.

\begin{tabular}{|c|c|c|c|c|c|c|}
\hline Test & $\begin{array}{c}\text { Sample } \\
\text { material }\end{array}$ & $\begin{array}{c}\text { Fibre } \\
\text { orientation }\end{array}$ & Sidewall & $\begin{array}{c}\text { Orientation } \\
\text { joiningplane }\end{array}$ & IR Scale & Duration \\
\hline & & $\begin{array}{c}\text { Relative to flow } \\
\text { direction }\end{array}$ & coating & $\begin{array}{c}\text { Relative to } \\
\text { vertical }\end{array}$ & & $\mathrm{s}$ \\
\hline $106115 \mathrm{~L}$ & $\mathrm{C} / \mathrm{C}$ & Parallel $\pm 45^{\circ}$ & Open & $45^{\circ}$ & $-20 / 120^{\circ} \mathrm{C}$ & 5 \\
\hline $107115 \mathrm{~L}$ & $\mathrm{C} / \mathrm{C}$ & Parallel $\pm 45^{\circ}$ & Open & $45^{\circ}$ & $-20 / 120^{\circ} \mathrm{C}$ & 13 \\
\hline $108115 \mathrm{~L}$ & $\mathrm{C} / \mathrm{C}$ & Parallel $\pm 45^{\circ}$ & Closed & $45^{\circ}$ & $-20 / 120^{\circ} \mathrm{C}$ & 11 \\
\hline $109115 \mathrm{~L}$ & $\mathrm{C} / \mathrm{C}$ & Parallel $\pm 45^{\circ}$ & Closed & $45^{\circ}$ & $80 / 500^{\circ} \mathrm{C}$ & 16 \\
\hline $110115 \mathrm{~L}$ & $\mathrm{C} / \mathrm{C}$ & Parallel $\pm 45^{\circ}$ & Closed & $45^{\circ}$ & $80 / 500^{\circ} \mathrm{C}$ & 14 \\
\hline $111115 \mathrm{~L}$ & $\mathrm{C} / \mathrm{C}$ & Parallel $\pm 45^{\circ}$ & Closed & $90^{\circ}$ & $80 / 500^{\circ} \mathrm{C}$ & 48 \\
\hline $112115 \mathrm{~L}$ & $\mathrm{C} / \mathrm{C}$ & Parallel $\pm 45^{\circ}$ & Closed & $90^{\circ}$ & $80 / 500^{\circ} \mathrm{C}$ & 61 \\
\hline $113115 \mathrm{~L}$ & $\mathrm{C} / \mathrm{C}$ & Parallel $0^{\circ} / 90^{\circ}$ & Closed & $90^{\circ}$ & $80 / 500^{\circ} \mathrm{C}$ & 8 \\
\hline $114115 \mathrm{~L}$ & $\mathrm{C} / \mathrm{C}$ & Parallel $0^{\circ} / 90^{\circ}$ & Closed & $90^{\circ}$ & $80 / 500^{\circ} \mathrm{C}$ & 29 \\
\hline $115115 \mathrm{~L}$ & $\mathrm{C} / \mathrm{C}$ & Parallel $\pm 45^{\circ}$ & Closed & $90^{\circ}$ & $80 / 500^{\circ} \mathrm{C}$ & 31 \\
\hline $116115 \mathrm{~L}$ & $\mathrm{C} / \mathrm{C}$ & Parallel $\pm 45^{\circ}$ & Closed & $90^{\circ}$ & $80 / 500^{\circ} \mathrm{C}$ & 21 \\
\hline
\end{tabular}

7

American Institute of Aeronautics and Astronautics 
The sequence of infrared images in Fig. 8 was made during test $111115 \mathrm{~L}$ and shows that the coolant just started to emerge from the surface in Fig. 8a when the sample reaches the test location at $t=0$. During the first 3 seconds the coolant flow succeeds to cover almost the complete surface area with emerging water shown in Fig. 8b. Only at the right and left edges surface coverage is reduced in Fig. 8c indicated by increased surface temperature. The coolant slowly covers then also the remaining surface on the left of the sample in Fig. 8d but this remains the situation until the end of the test shown in Fig. 8e. There was almost a small hot area on the right side until the end of the test.

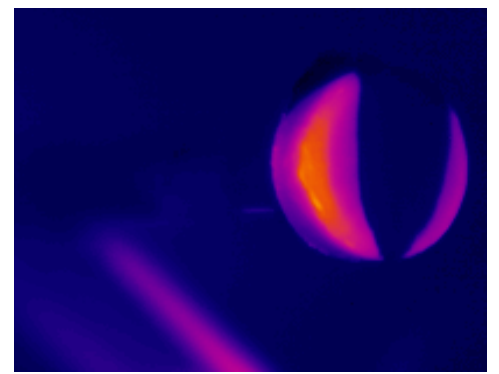

a)

Figure 8a. Infrared image at $\mathrm{t}=0$

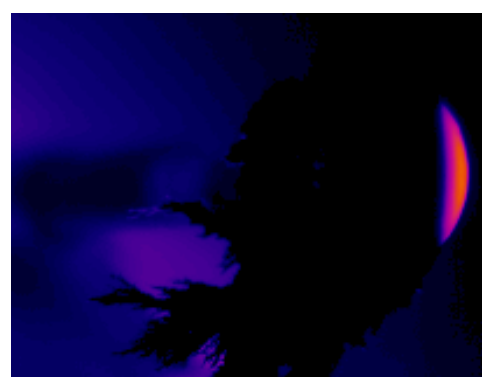

d)

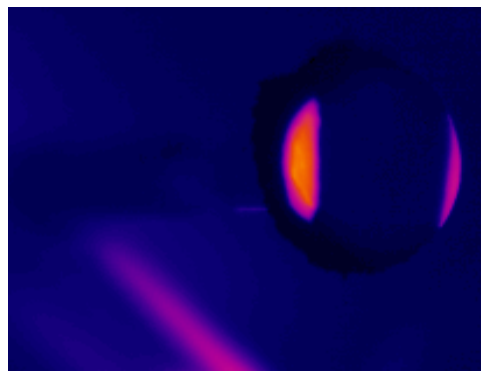

b)

Figure 8b. Infrared image at $\mathrm{t}=3 \mathrm{~s}$

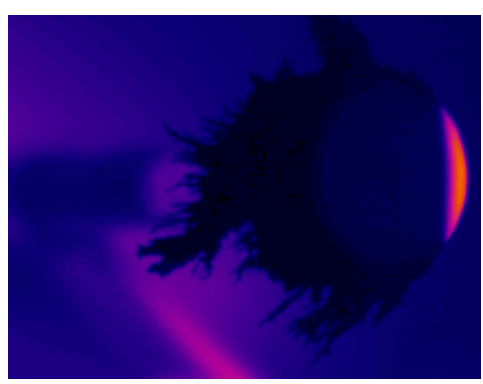

e)

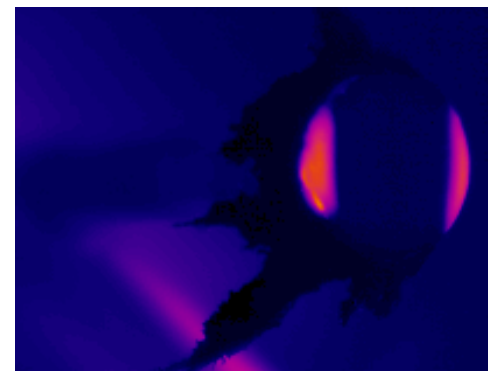

c)

Figure 8c. Infrared image at $\mathrm{t}=10 \mathrm{~s}$ $800.0^{\circ} \mathrm{C}$

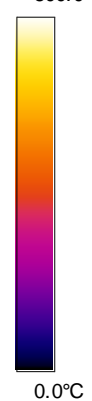

$0.0^{\circ} \mathrm{C}$

Figure 8d. Infrared image at $t=30 s \quad$ Figure 8e. Infrared image at $t=48 s$

During the tests of the $\mathrm{C} / \mathrm{C}$ samples with fibers parallel to the flow, a good cooling could always be achieved on the center area of the sample whereas the edges remained partially hot. A typical plot of the mass flow, the pressure and the reservoir temperatures is given for test 112115L in Fig. 9 and Fig. 10.

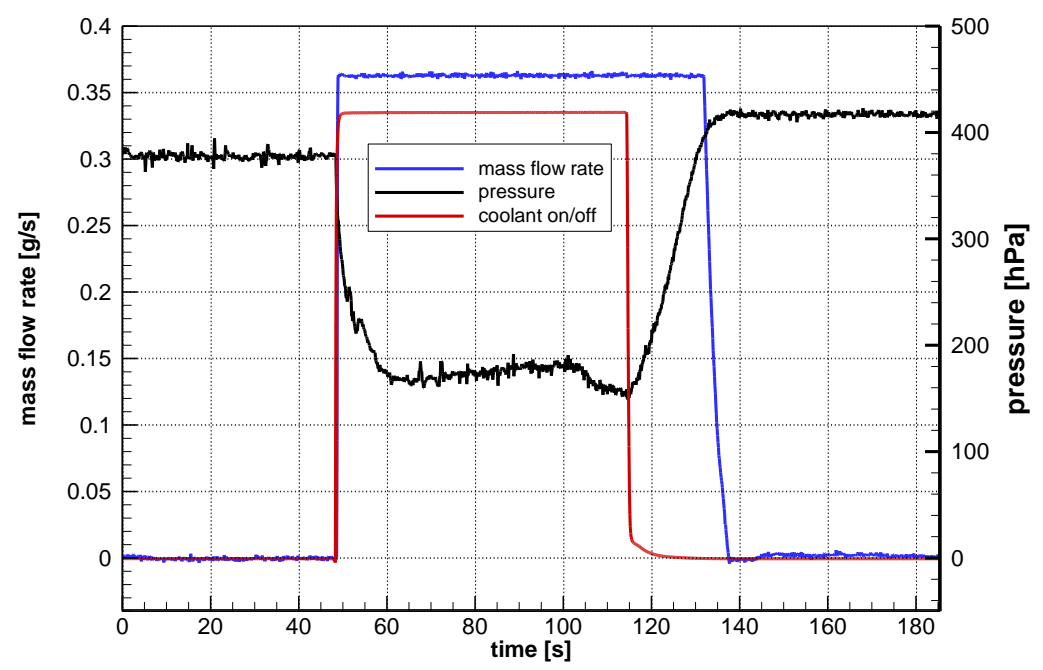

Figure 9. Mass flow and reservoir pressure for test 112115L.

8

American Institute of Aeronautics and Astronautics 


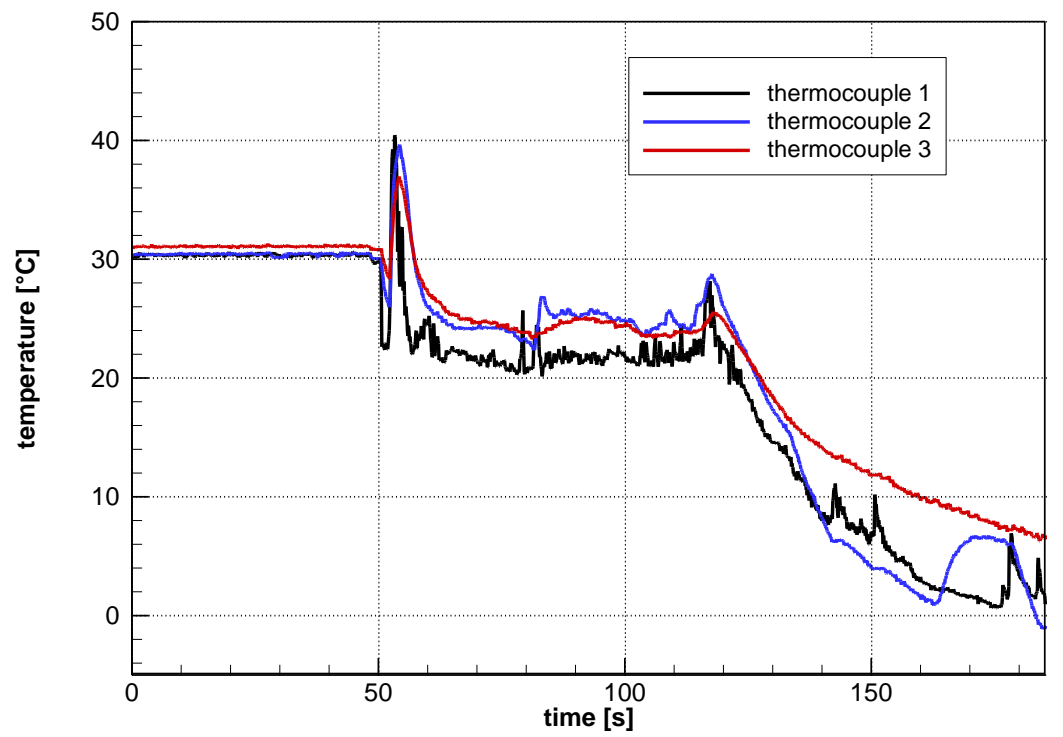

Figure 10. Reservoir temperature for test 112115L.

The hot spots at the sample edges are related to the vertical fibre orientation that inhibits direct coolant flow in horizontal direction. The dark colour at the sample's periphery indicates ice formation at the edge. The amount of ice is increasing with time forming dendrites propagating outward and backward. As the photograph in Fig. 11 indicates the coolant is emerging in liquid state from the front surface freezing during expansion around the shoulder at the upstream end of the side wall.

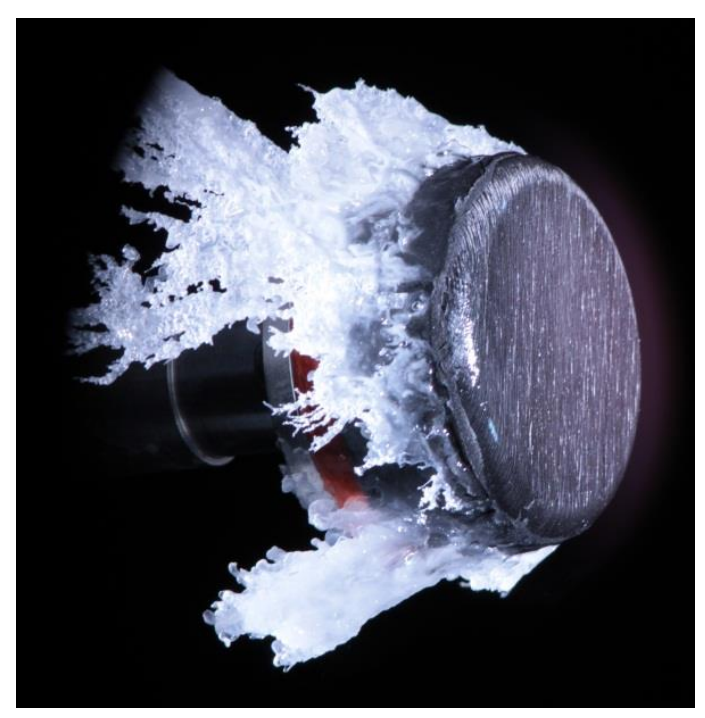

Figure 11. C/C sample with parallel fibre orientation during testing. 


\section{B. C/C Samples with Perpendicular Fiber Orientation}

More tests were conducted with samples having the fibers in normal direction to the flow. In Table 5 an overview about these tests is given.

Table 5. Overview about tests conducted with samples having the fibers normal to the flow.

\begin{tabular}{|c|c|c|c|c|c|c|c|}
\hline Test & Test \# & Sample & Material & $\begin{array}{l}\text { Fibre } \\
\text { direction } \\
\text { rel. to the } \\
\text { flow }\end{array}$ & $\begin{array}{l}\text { Reservoire } \\
\text { pressure } \\
{[\mathrm{hPa}]}\end{array}$ & $\begin{array}{l}\text { Measure- } \\
\text { ment range } \\
\text { flowmeter }\end{array}$ & Duration [s] \\
\hline 170112_01 & 1 & C/C-1 & $\mathrm{C} / \mathrm{C}$ & normal & 500 & Small & 66 \\
\hline 170112_02 & 2 & C/C-1 & $\mathrm{C} / \mathrm{C}$ & normal & 400 & Small & 73 \\
\hline 180112_01 & 3 & C/C-1 & $\mathrm{C} / \mathrm{C}$ & normal & 330 & Large & 61 \\
\hline 180112_02 & 4 & C/C-1 & $\mathrm{C} / \mathrm{C}$ & normal & 275 & Large & 14 \\
\hline 180112_03 & 5 & C/C-1 & $\mathrm{C} / \mathrm{C}$ & normal & 310 & Large & 252 \\
\hline 180112_04 & 6 & $\mathrm{C} / \mathrm{C}-1$ & $\mathrm{C} / \mathrm{C}$ & normal & $310-170$ & Large & 373 \\
\hline 190112_01 & 7 & C/C-SiC-3 & C/C-SiC & parallel & 1270 & Large & 16 \\
\hline 190112_02 & 8 & $\mathrm{C} / \mathrm{C}-\mathrm{SiC}-3$ & C/C-SiC & parallel & 1600 & Large & 16 \\
\hline 190112_03 & 9 & $\mathrm{C} / \mathrm{C}-\mathrm{SiC}-3$ & C/C-SiC & parallel & 2000 & Large & 82 \\
\hline 190112_04 & 10 & C/C-SiC-3 & $\mathrm{C} / \mathrm{C}-\mathrm{SiC}$ & parallel & 2000 & Large & $\begin{array}{l}19 ; \\
8(\mathrm{dt}=24)\end{array}$ \\
\hline 190112_05 & 11 & C/C-1 & $\mathrm{C} / \mathrm{C}$ & normal & 320 & Small & 9 \\
\hline 200112_01 & 12 & C/C-1 & $\mathrm{C} / \mathrm{C}$ & normal & 360 & Small & $3 ; 2(\mathrm{dt}=78)$ \\
\hline 200112_02 & 13 & C/C-1 & $\mathrm{C} / \mathrm{C}$ & normal & $490-190$ & Small & 265 \\
\hline 200112_03 & 14 & C/C-1 & $\mathrm{C} / \mathrm{C}$ & normal & $490-210$ & Small & 175 \\
\hline 200112_04 & 15 & C/C-1 & $\mathrm{C} / \mathrm{C}$ & normal & $490-210$ & Small & 306 \\
\hline 200112_05 & 16 & C/C-1 & $\mathrm{C} / \mathrm{C}$ & normal & $490-210$ & Small & 189 \\
\hline 200112_06 & 17 & C/C-3 & $\mathrm{C} / \mathrm{C}$ & normal & $460-225$ & Small & 90 \\
\hline 200112_07 & 18 & C/C-3 & $\mathrm{C} / \mathrm{C}$ & normal & $\begin{array}{l}360 ; \\
530-440\end{array}$ & Small & $\begin{array}{l}18 ; \\
41(\mathrm{dt}=150)\end{array}$ \\
\hline
\end{tabular}

A coating on the circumferential face of the sample cylinders was applied during the tests to prevent coolant from exiting on the cylindrical face of the sample and thus compromising the data with regard to the mass flow measurement that should be related to the front face.

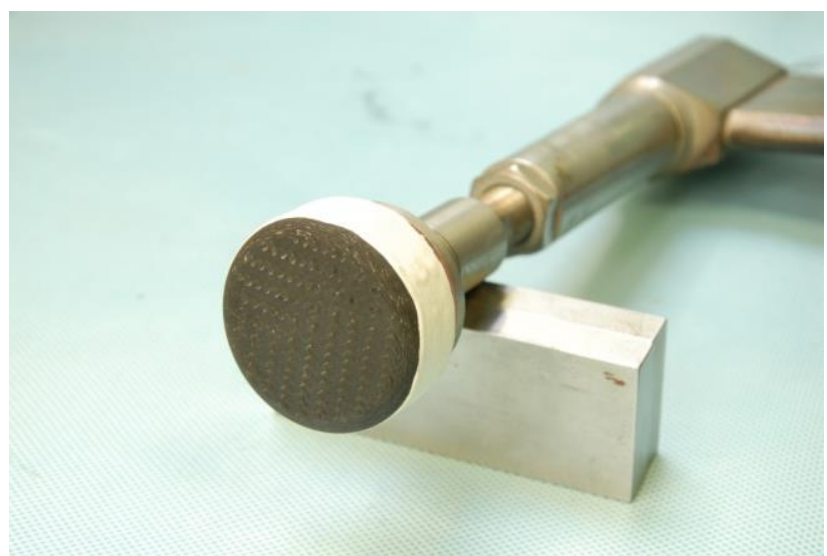

Figure 12. Sample C/C-1 with applied circumferential coating before test.

A thermal imaging system with an unobstructed view on the surface of the sample was used generating the images in Fig. 13 for example. Note that the camera was mounted upside down to the tunnel front face due to very tight space there which does not allow something else.

The goal of the tests was to find the conditions of minimum coolant flow necessary to maintain a steady-state cooled situation on the sample surface. Initially the tests were conducted with fixed setting for the reservoir pressure adjusted before the test which translates directly into a certain mass flow due to the pressure difference and the given material properties. With this approach the first tests resulted in a well cooled surface that could be maintained over the whole test time. The reservoir pressure was then reduced from one test to the next and a problem occurred. 
When the valve for the water supply is opened, the pressure drops initially by a large value and then recovers due to the fact that a portion of the supply line still has to be filled with water. When the pressure recovers and the values are close to the critical ones of minimum coolant supply it very likely happens that the coolant supply is already too low early in the test and the sample starts to heat up which can not be cooled down again.

Therefore the procedure was changed and the pressure was gradually reduced in the running test, making sure that there is always enough coolant available in the beginning when the pressure drop occurs.

Test 6 was the first test carried out with that approach. Figure 13 shows the reservoir pressure and mass flow data. The mass flow data was recorded with the flow meter that has a larger measurement range. In the earlier tests with starting pressure of $300 \mathrm{mbar}$ could be carried out with steady-state conditions, another one with 280 mbar starting pressure was not successful. Thus the pressure was set to $300 \mathrm{mbar}$ starting value and reduced stepwise in the test until a hot spot developed.

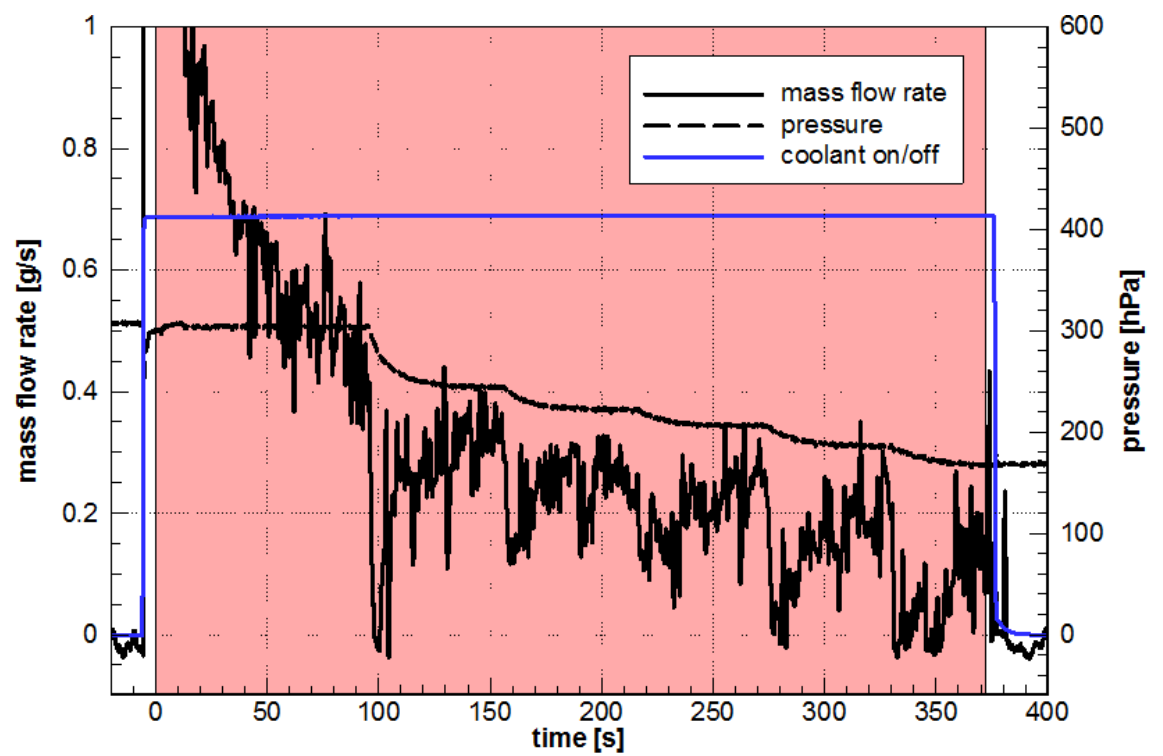

Figure 13. Mass flow and reservoir pressure from test 6.

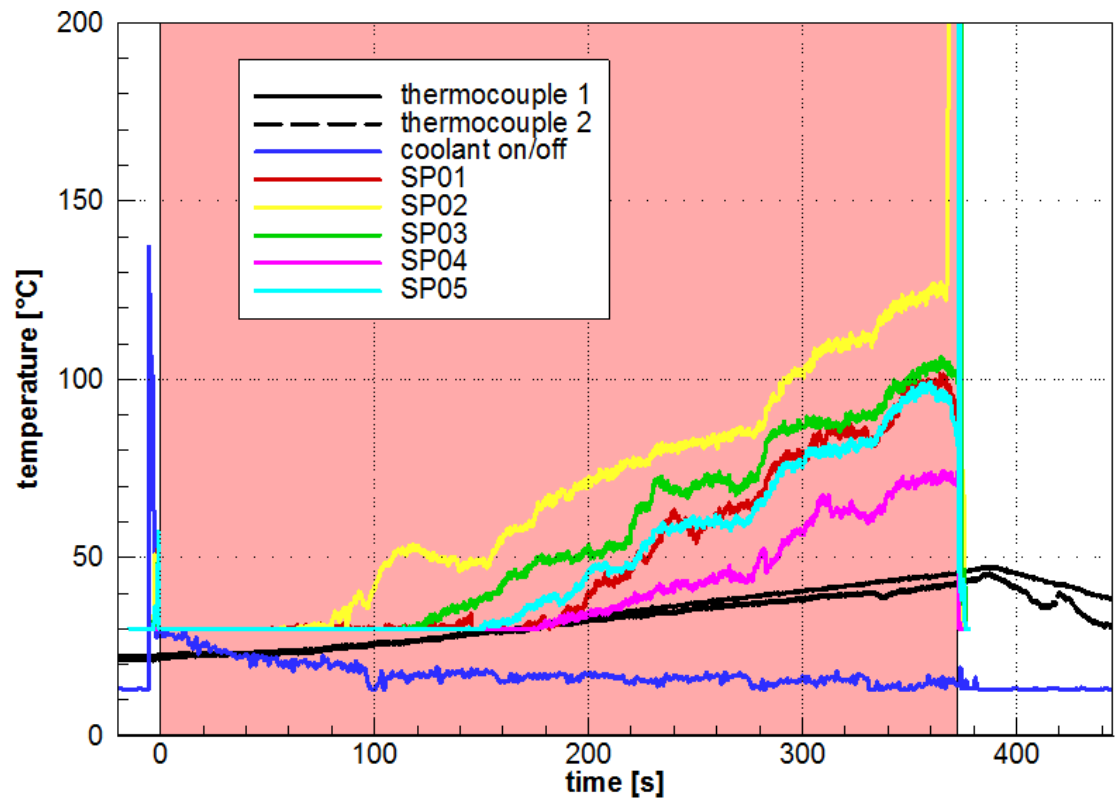

Figure 14. Reservoir and surface temperatures from test 6. 
In Fig. 13 it can be seen how the pressure is reduced gradually in small steps with corresponding mass flow reductions. In Fig. 14 it can be seen that the surface temperatures in fact start to rise slowly after $90-150 \mathrm{~s}$ to values between $70^{\circ} \mathrm{C}$ and $120^{\circ} \mathrm{C}$ at the test end at $373 \mathrm{~s}$. Also the reservoir temperature increases slowly up to almost $50^{\circ} \mathrm{C}$. The test procedure proved to work well, however, the resolution of the flow meter was not good in the measurement range at the end of the test, so it was decided to switch to the flow meter with smaller range and continue the testing with the new approach.

Of the tests conducted, two successful runs with good results will be discussed in detail. First, test 15 gave a very good indication about the limit condition for minimum mass flow.

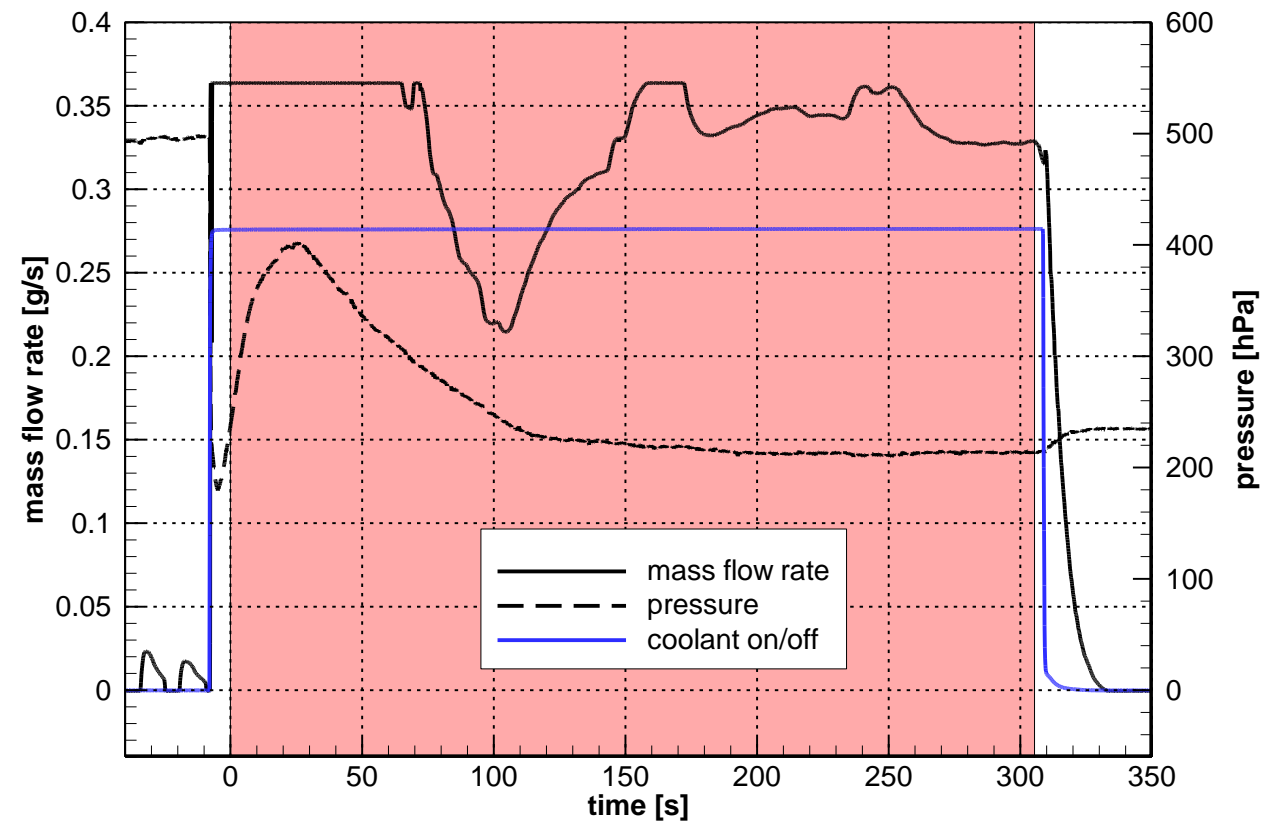

Figure 15. Mass flow and reservoir pressure from test 15.

In Fig. 15 it is shown that the starting pressure was 490 mbar. After the initial drop it recovered to $400 \mathrm{hPa}$ and was then gradually reduced in very small steps. The mass flow tended to increase towards and above the meter limit of $0.36 \mathrm{~g} / \mathrm{s}$ but came back below after some seconds and remained close to that value up to the end of the test. After $306 \mathrm{~s}$ the pressure had been reduced to $215 \mathrm{hPa}$ and the mass flow was at $0.33 \mathrm{~g} / \mathrm{s}$ relatively constant for some 25 seconds.

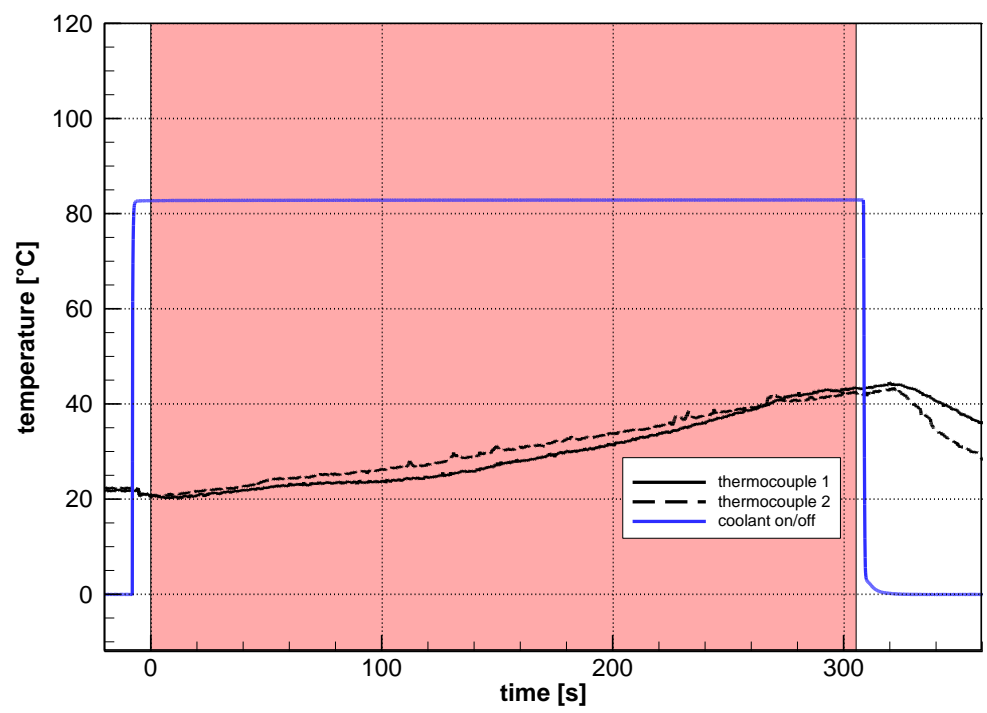

Figure 16. Reservoir temperatures from test 15.

12

American Institute of Aeronautics and Astronautics 
The reservoir temperatures increased again slowly to $42^{\circ} \mathrm{C}$ at the end of the test as presented in Fig. 16. Figures $17 \mathrm{a}$ and $17 \mathrm{~b}$ show thermal images taken during the test.

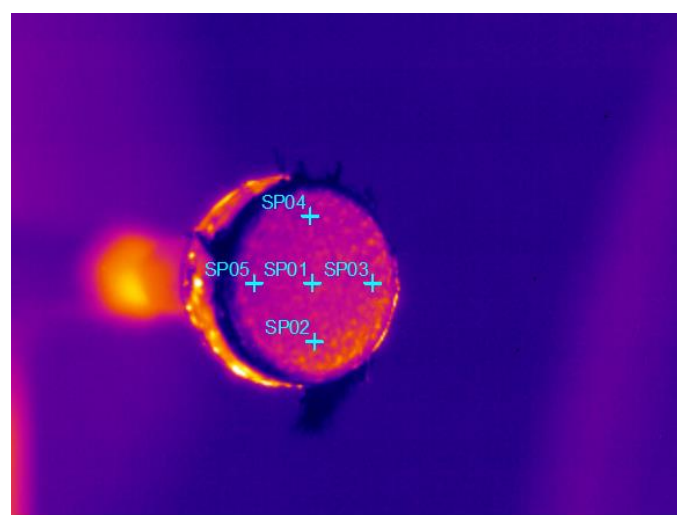

a)

Figure 17a. Sample during test 15 with sufficient cooling.

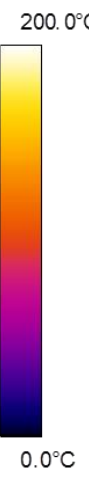

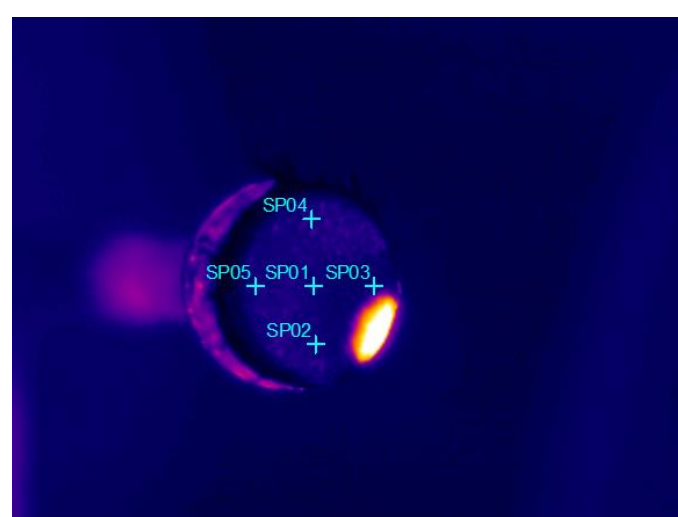

$700.0^{\circ} \mathrm{C}$

b)

Figure $17 \mathrm{~b}$. Sample during test 15 at the beginning of a hot sport formation.

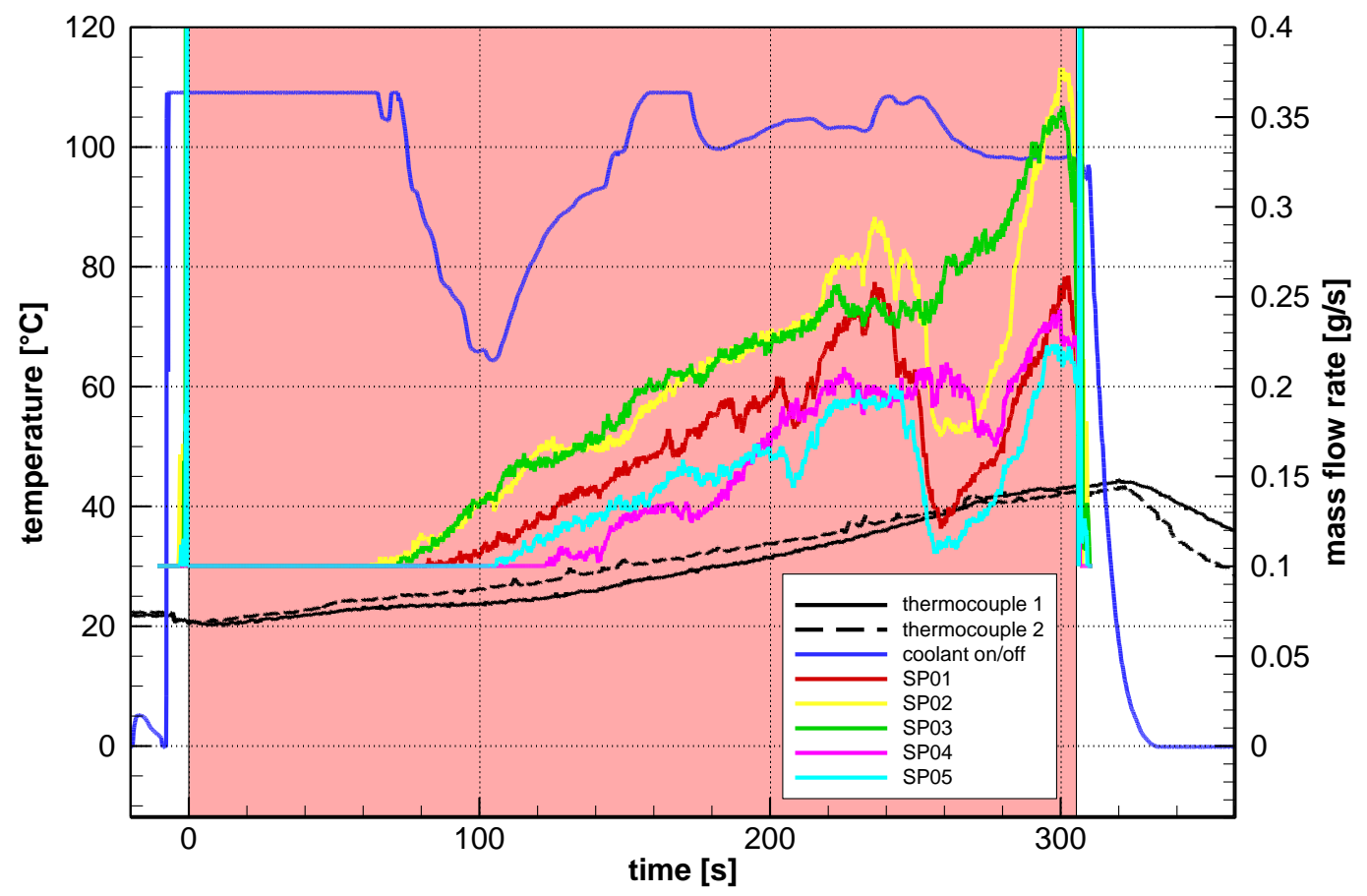

Figure 18. Mass flow, surface and reservoir temperatures from test 15.

The surface temperatures started to increase at $70 \mathrm{~s}$ slowly with a rate of $0.3^{\circ} \mathrm{C} / \mathrm{s}$ to approximately $60-80{ }^{\circ} \mathrm{C}$ at SP02 and SP03 which are close to the upper left edge that sees heat first when inserted into the flow, see Fig. 18. A similar increase with a time-shift can be observed at the other locations SP01, SP05 and SP04 (in that order). Regarding the water steam pressure at the conditions of the test with approximately $30 \mathrm{hPa}$ stagnation pressure it can be concluded that there was steam exiting from the sample surface.

Interestingly, a temperature drop is exhibited at all points except for SP03 at $240 \mathrm{~s}$ into the test. The temperature decreases by up to $37^{\circ} \mathrm{C}$ (SP01) over a time of $20-40 \mathrm{~s}$ to increase again after that event and comes back to values between $65-110^{\circ} \mathrm{C}$ at $300 \mathrm{~s}$. The reason for this sudden drop in temperature is not completely clear, there is a very small variation in the mass flow at that time from $0.34-0.36 \mathrm{~g} / \mathrm{s}$, however, it seems difficult to explain it with this small change in coolant flow. 
Test 16 was meant to confirm the previous results but in addition it served as a test to find out if the sudden temperature increase that started with the development of a hot spot could be controlled via rapidly increasing the reservoir pressure again to get more coolant to the sample.

In Fig. 19 it can be seen that the initial pressure was again set to $490 \mathrm{hPa}$ which fell shortly to $200 \mathrm{hPa}$ after insertion. After the recovery to $400 \mathrm{hPa}$ it was continuously reduced to $220 \mathrm{hPa}$ and then further very carefully to $210 \mathrm{hPa}$.

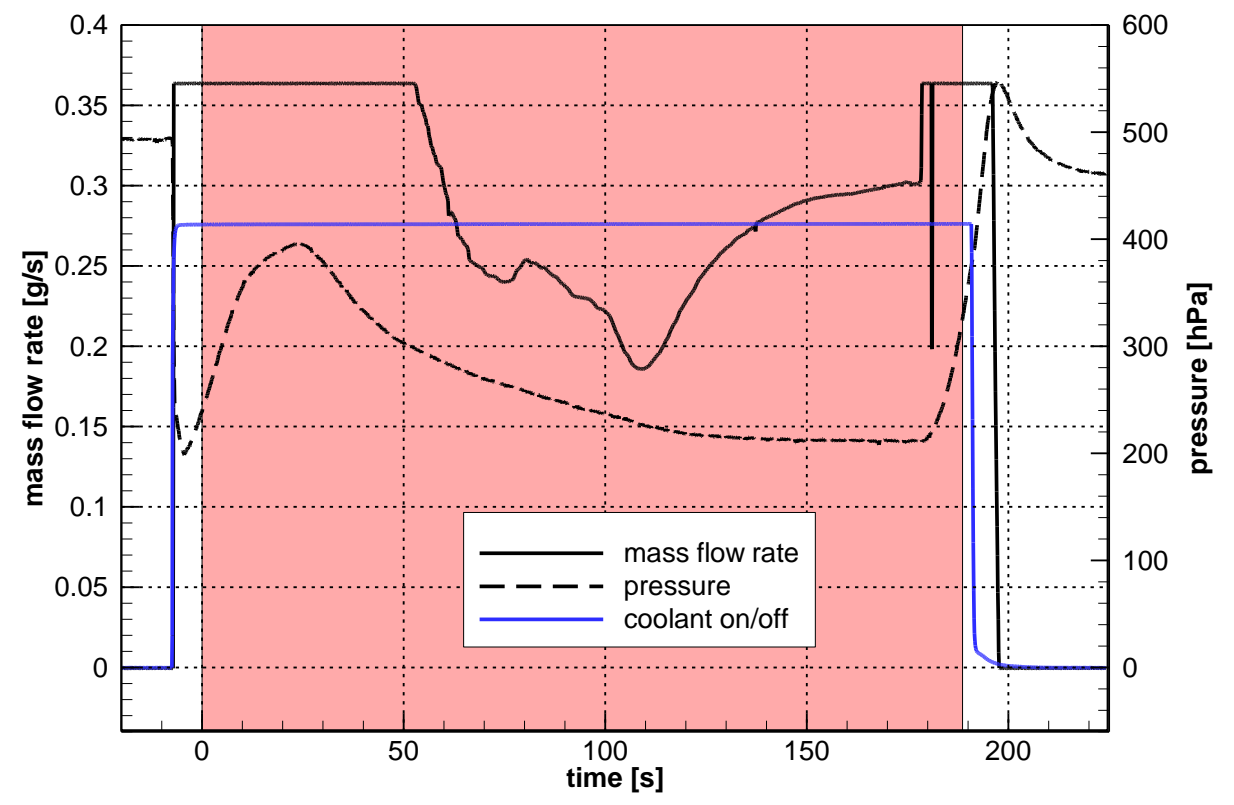

Figure 19. Mass flow and reservoir pressure from test 16.

The mass flow was above $0.36 \mathrm{~g} / \mathrm{s}$ initially, then fell to $0.18 \mathrm{~g} / \mathrm{s}$ due to the rapid pressure decrease and recovered to $0.3 \mathrm{~g} / \mathrm{s}$ when the pressure had reached $210 \mathrm{hPa}$. Towards the EOT when the pressure was stable at $210 \mathrm{hPa}$ the mass flow was practically steady at $0.3 \mathrm{~g} / \mathrm{s}$.

In Fig. 20a and 20b two images are shown the illustrate the condition at the beginning of the test with ice dendrite formation due to high coolant mass flow and close to the end of the test with the circumference beginning to heat up and the formation of speckles of higher temperature.

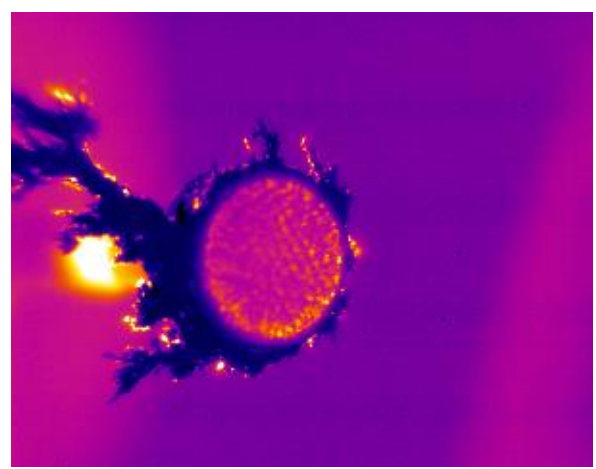

a)

Figure 20a. Infrared image during test 16 and high coolant flow rate.

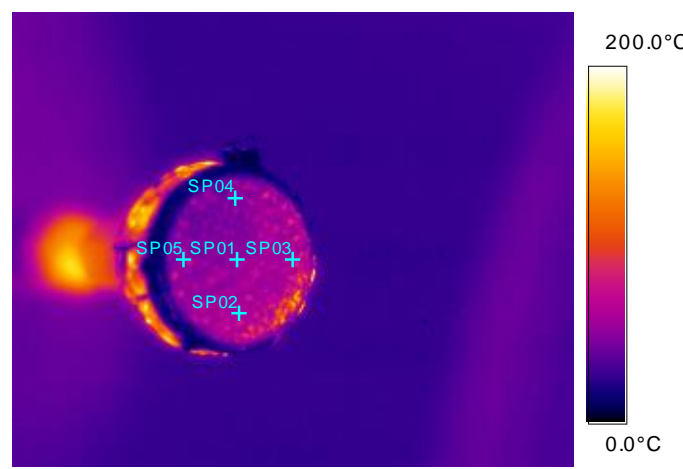

b)

Figure 20b. Infrared image of a $\mathrm{C} / \mathrm{C}$ sample with fibers perpendicular and low coolant flow rate.

The development of the surface tempertaures is very nice in this test, see Fig. 21. Corresponding to the mass flow which increases after $110 \mathrm{~s}$ and reaches a plateau at 180s, the surface temperatures at SP02, SP03 and SP05 increase up to $120 \mathrm{~s}$ and are then relatively constant up to the end at a value of $50-60{ }^{\circ} \mathrm{C}$. Temperatures at SP01 and SP04 show an increasing trend all the time. At $180 \mathrm{~s}$ a hot spot develops in the upper region and the temperature at SP02 takes off to high values. Also in this test the conclusion was that there was steam exiting the sample surface due to the temperatures and the given stagnation pressure which was quite low. 
The immediate opening of the valve to increase the pressure and get the hot spot under control was not successful. In fact the temperatures at all locations except for SP02 fall for a short time, however, the hot spot at SP02 could not be controlled again and continues to expand, eventually triggering a global temperature rise.

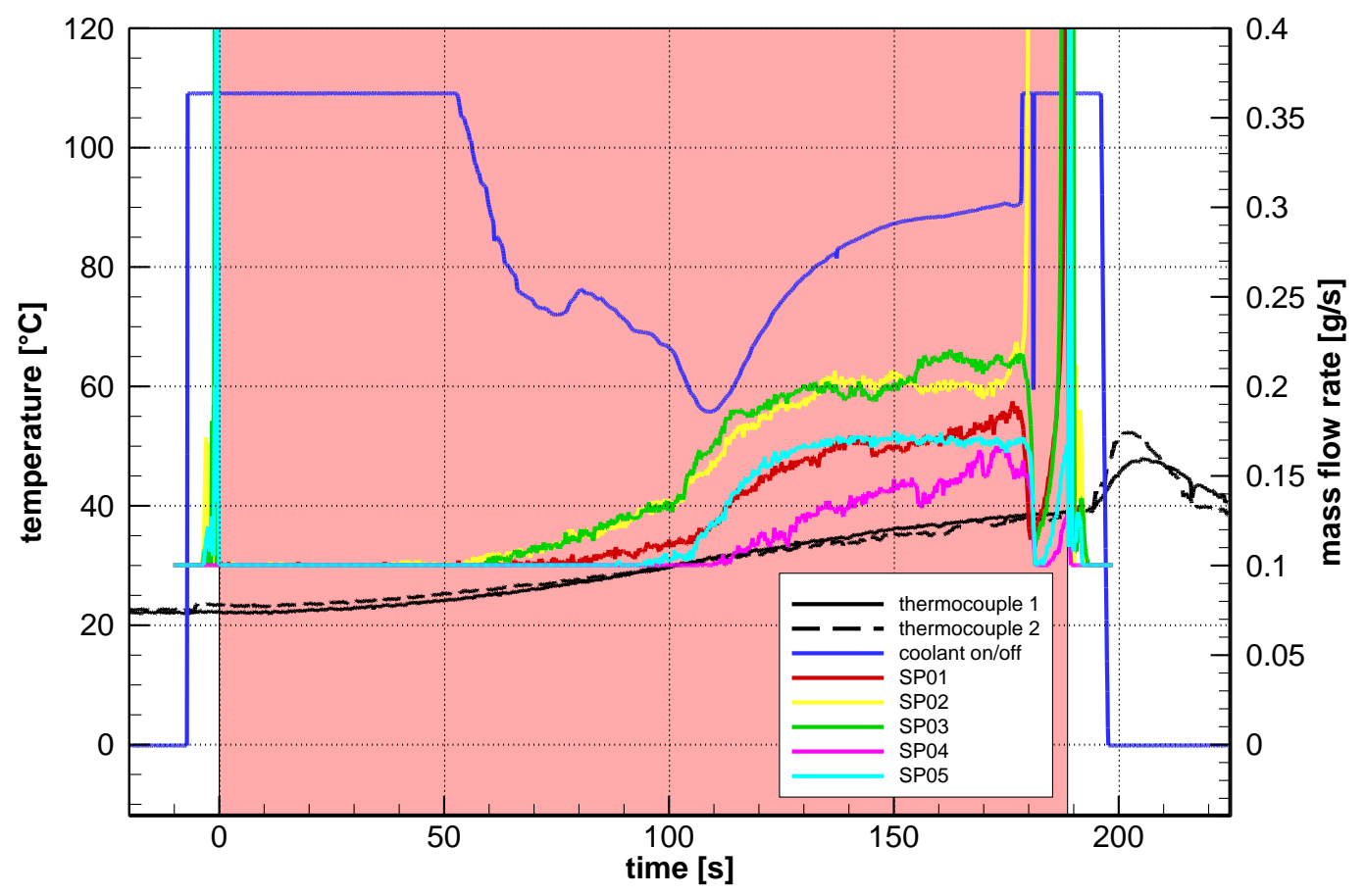

Figure 21. Mass flow, surface and reservoir temperatures from test 16.
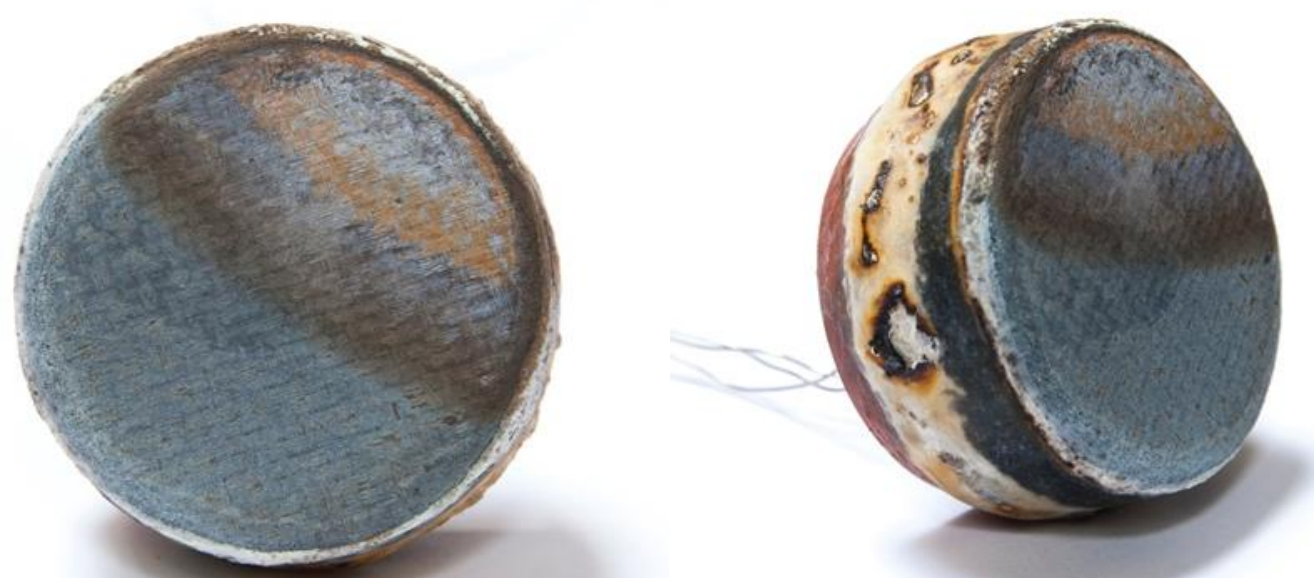

Figure 22. Sample $\mathrm{C} / \mathrm{C}-1$ after test 16 . There was a certain amount of oxidation in the upper region of the sample where the hot spot had formed multiple times. The coating on the circumference was performing well and it was possible to re-apply it between tests. 


\section{Oxide Fiber CMC with parallel Fiber Orientation}

The Samples made of oxide fibre CMC material were applied with parallel fibre orientation only. Table 6 gives a detailed overview about the tests conducted with these types of samples.

Table 6. Samples made from oxide fiber CMC.

\begin{tabular}{|c|c|c|c|c|c|c|}
\hline Test \# & Sample & $\begin{array}{c}\text { Fibre } \\
\text { Orientation }\end{array}$ & Pressure [hPa] & Coolant & $\begin{array}{c}\text { Range } \\
\text { Flowmeter }\end{array}$ & $\begin{array}{c}\text { Duration } \\
\text { [s] }\end{array}$ \\
\hline 19 & $\mathrm{Al}-\mathrm{Ox}-1$ & parallel & 470 & water & large & 47 \\
\hline 20 & $\mathrm{Al}-\mathrm{Ox}-1$ & parallel & 355 & water & large & 49 \\
\hline 21 & $\mathrm{Al}-\mathrm{Ox}-1$ & parallel & 320 & water & large & 51 \\
\hline 22 & $\mathrm{Al}-\mathrm{Ox}-1$ & parallel & 255 & water & large & 49 \\
\hline 23 & $\mathrm{Al}-\mathrm{Ox}-1$ & parallel & 200 & water & large & 46 \\
\hline 24 & $\mathrm{Al}-\mathrm{Ox}-1$ & parallel & 160 & water & large & 2 \\
\hline 25 & $\mathrm{Al}-\mathrm{Ox}-2$ & parallel & 210 & water & large & 12 \\
\hline 26 & $\mathrm{Al}-\mathrm{Ox}-2$ & parallel & 260 & water & large & 3 \\
\hline 27 & $\mathrm{Al}-\mathrm{Ox}-2$ & parallel & 300 & water & large & 3 \\
\hline 28 & $\mathrm{Al}-\mathrm{Ox}-2$ & parallel & 510 & water & large & 64 \\
\hline 29 & $\mathrm{Al}-\mathrm{Ox}-2$ & parallel & 410 & water & small & 6 \\
\hline 30 & $\mathrm{Al}-\mathrm{Ox}-2$ & parallel & $500-160$ & water & small & 538 \\
\hline 31 & $\mathrm{Al}-\mathrm{Ox}-2$ & parallel & $500-155$ & water & small & 302 \\
\hline 32 & Al-Ox-2 & parallel & $480-160$ & water & small & $48 ; 812$ \\
\hline 33 & Al-Ox-2 & parallel & $1400-2650$ & nitrogen & small & $11 ; 10 ; 19 ; 27$ \\
\hline 34 & $\mathrm{C} / \mathrm{C}$ & perpendicular & $2000-2500$ & nitrogen & small & $2 ; 3$ \\
\hline 35 & Al-Ox-1 & parallel & $2000-2900$ & nitrogen & small & $9 ; 26 ; 28 ; 21$ \\
\hline 36 & C/C-SiC & perpendicular & 2400 & water & small & 6 \\
\hline
\end{tabular}

As the series of infrared images in Fig. 22 a-d indicates the thermal behavior was again dominated by the fibre orientation as seen for the $\mathrm{C} / \mathrm{C}$ samples. Due to the high permeability of the surface there is only partial surface coverage in the beginning. The mass flow was initially high at the saturation level of $0.36 \mathrm{~g} / \mathrm{s}$ of the flow meter. After $300 \mathrm{~s}$ it dropped below that level. At a pressure of $160 \mathrm{hPa}$ there was a phase of about $40 \mathrm{~s}$ with constant pressure and relatively constant mass flow of $0.27 \mathrm{~g} / \mathrm{s}$.

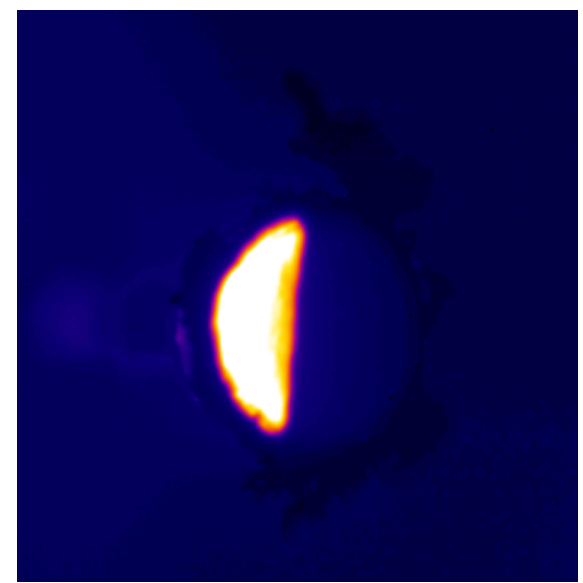

a)

Figure 22a. Infrared image of an oxide fibre CMC sample with parallel fiber orientation at $\mathbf{t}=\mathbf{5} \mathrm{s}$.

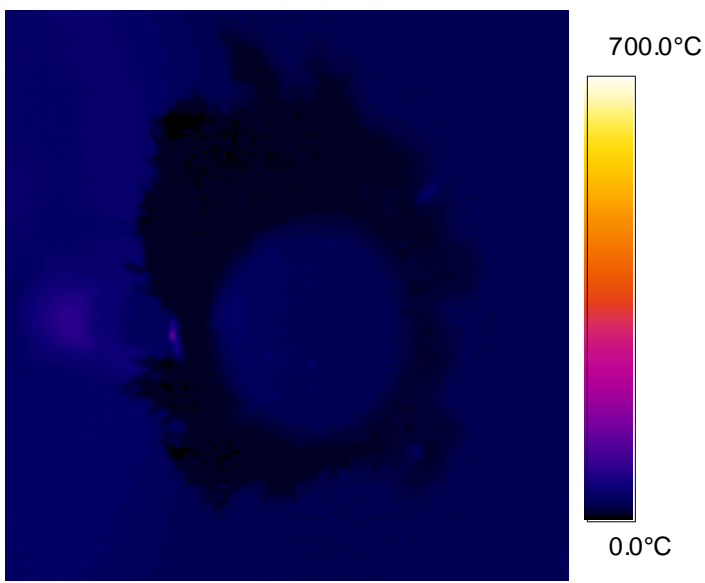

b)

Figure 22b. Infrared image of an oxide fibre CMC sample with parallel fiber orientation at $t=20 \mathrm{~s}$. 


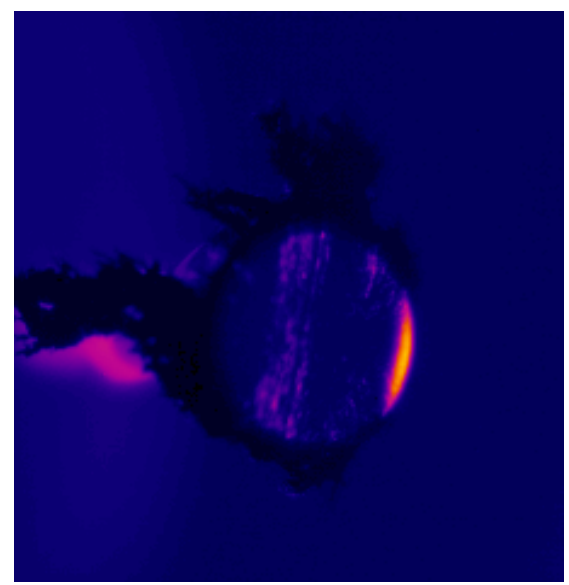

c)

Figure 22c. Infrared image of an oxide fibre CMC sample with parallel fiber orientation at $\mathbf{t}=\mathbf{3 3 0} \mathrm{s}$.

Figure 11: Series of

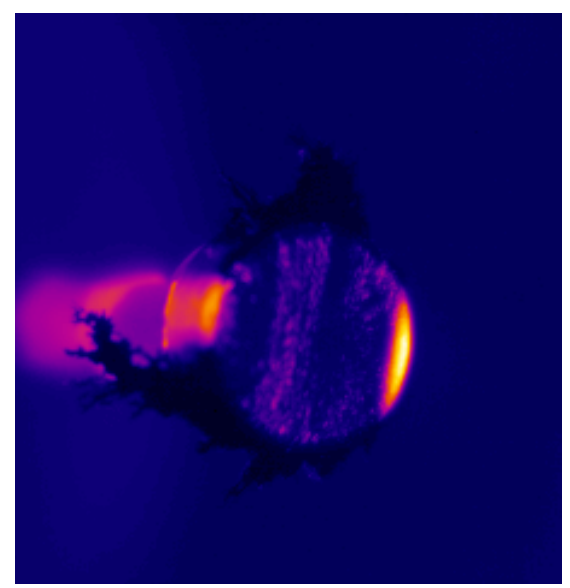

d)

Figure 22d. Infrared image of an oxide fibre CMC sample with parallel fiber orientation at $\mathbf{t}=\mathbf{5 0 0} \mathrm{s}$.

A cold surface was established after a few seconds into the test. This situation was maintained for roughly 5 min during which the pressure was reduced. When the pressure had come down to roughly $180 \mathrm{hPa}$ there were first signs of a hot edge developing on the sample. Approximately at the same time the surface temperatures began to rise noticeably. This trend continued with growing of the hot edges and rising surfaces temperature and eventually the front surface became hot altogether with a steep temperature rise. The reservoir temperature started to rise from the beginning of the test and had reached almost $60^{\circ} \mathrm{C}$ at the end of the test.

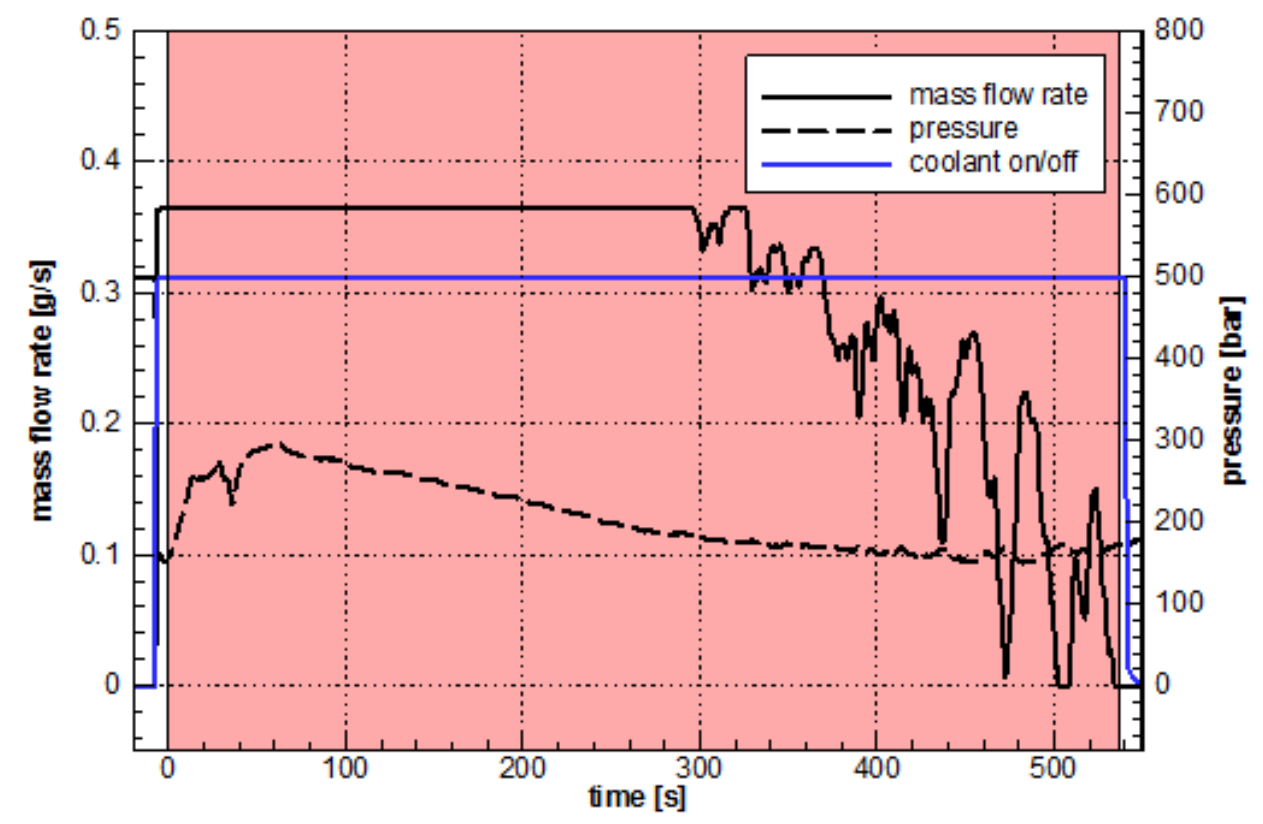

Figure 23. Mass flow and reservoir pressure from test 30. 


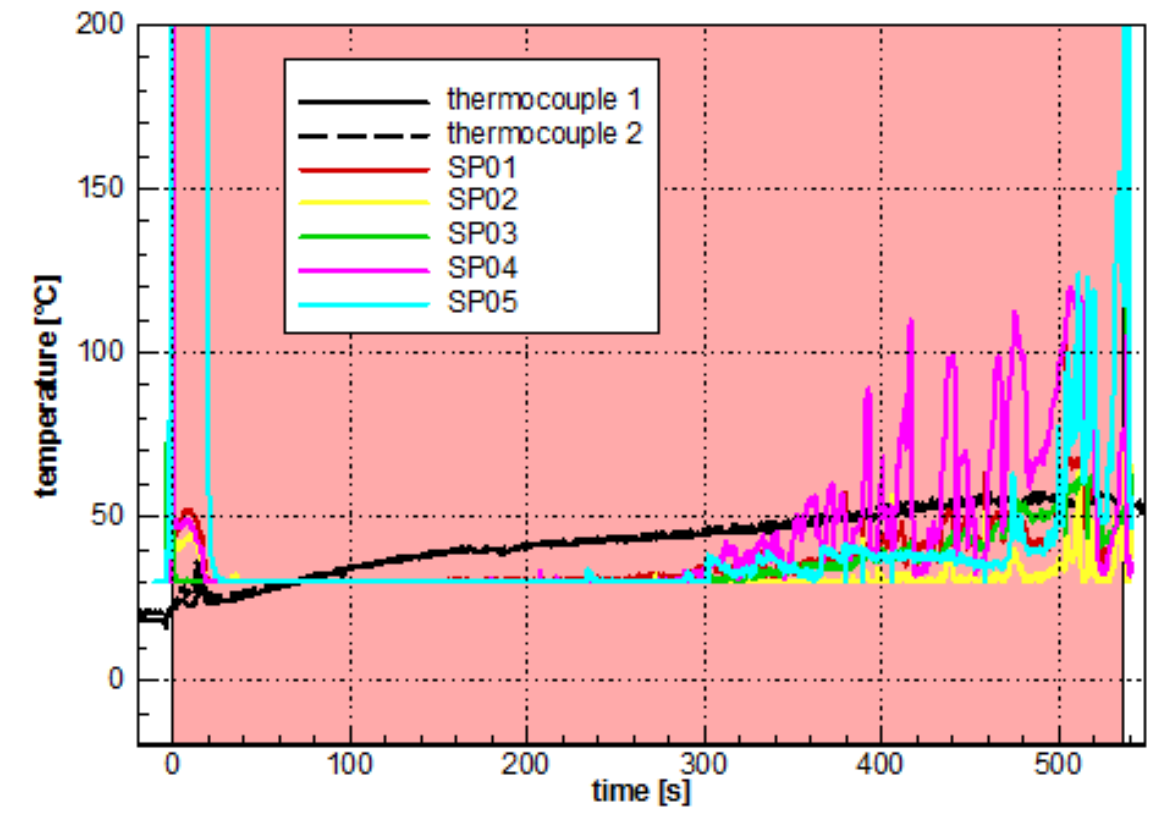

Figure 24. Surface and reservoir tempertures from test 30.

\section{Conclusion}

High speed sustained atmospheric flight creates high thermal loads at the tip, leading edges, intake ramps or engine structures of the flight vehicle. However, sharp edges are mandatory for these vehicles in order to obtain the required aerodynamic performance. To provide technical solutions for these problems, the concept of using porous ceramic matrix composite (CMC) materials in combination with active cooling by transpiration was investigated. A screening test campaign was carried out to determine the basic parameters that are important for the use of the concept in a technical system focusing on liquid water as the coolant media.

A basic material selection was made at the beginning of the program. The main criteria to be regarded were permeability, availability and cost and also thermal properties. The final selection was $\mathrm{C} / \mathrm{C}$ material from DLR, C/C$\mathrm{SiC}$ also from DLR and and Aluminium-Oxide material by the company Walter Pritzkow Spezialkeramik.

The tests reported in this document were stagnation tests on flat samples with a diameter of $50 \mathrm{~mm}$. The front wall thickness was $8 \mathrm{~mm}$. The tests were carried out in the L3K arc jet facility of DLR Cologne in an environment of approximately $1 \mathrm{MW} / \mathrm{m}^{2}$ heat load. Good results were achieved in terms of mass flow data. A number of tests could be carried out at low supply pressures and low mass flow. A medium value of the lower limit mass flow is $0.33 \mathrm{~g} / \mathrm{s}$ at a pressure of $225 \mathrm{hPa}$ which is equal to $0.152 \mathrm{~kg} / \mathrm{m}^{2} \mathrm{~s}$.

With the aluminum oxide samples, a cold surface could also be maintained, however, it was not possible to establish a steady-state condition in terms of mass flow and supply pressure.

Wrapping up the observations made during these test campaigns it can be said that the transpiration cooling with liquid water is a very interesting technology that should be matured further. This can be done by developing the materials and by understanding the physical processes in the system better. The tests showed that the permeability is a decisive factor which drives the requirement for the supply pressure. Since it is a material property that is coupled to the fiber direction in the $\mathrm{CMC}$, the issue of the component layup becomes very important.

The tests with the $\mathrm{C} / \mathrm{C}$ samples showed that it is possible to maintain steady-state cooling over considerable times given the favorable properties of the $\mathrm{C} / \mathrm{C}$. Fiber orientation normal to the flow provided for a better distribution of the cooling. It was not possible to achieve the cooling via the capillary effect only. There has to be the right differential pressure applied.

In the case of $\mathrm{C} / \mathrm{C}-\mathrm{SiC}$ which was not discussed here in detail, cooling could only be achieved with fibers parallel to the flow. However, in that case the surface temperature could be held constant at $350{ }^{\circ} \mathrm{C}$ and presumably steam was partially acting as the coolant. These results are difficult to interpret and need validation. 
Since the $\mathrm{C} / \mathrm{C}$ material is basically susceptible to oxidation over $450{ }^{\circ} \mathrm{C}$ it would be an objective to develop a $\mathrm{C} / \mathrm{C}-\mathrm{SiC}$ material with a permeability that allows for its use with fibers oriented normal to the flow.

It seems very hard to control a system that always guarantees that liquid water is flowing to the surface. It would be very interesting to investigate the situation further where there is controlled boiling in the reservoir and the coolant is going through the wall as steam.

\section{Acknowledgments}

The authors gratefully want to acknowledge funding from the EU within the Seventh Framework Programme for the FAST20XX project under the grant agreement no. 233816.

In addition the authors want to acknowledge the great work performed by the technical team at DLR Stuttgart preparing the samples and by the team at DLR Cologne who ran the arc jets.

\section{References}

${ }^{1}$ J. J. Bertin, Hypersonic Aerothermodynamics, AIAA 1993, ISBN 978-1563470363

${ }^{2}$ H. Weihs, H. Hald, T. Reimer, I. Fischer, "Development of a CMC Nose Cap for X-38", IAF-01-I.3.01, $52^{\text {nd }}$ International Astronautical Congress, Toulouse, 2001

${ }^{3}$ H. Hald, P. Winkelmann, "Post Mission Analysis of the Heat Shield Experiment CETEX for the EXPRESS Capsule", IAF-97-I.4.01, $48^{\text {th }}$ IAF Congress, Turin, 1997

${ }^{4}$ T. Reimer, K. Stubicar, G. Koppenwallner, R. M. Müller-Eigner, S. Lein, A. Steinbeck, "Overview about the Instrumented Nose Assembly Development for the EXPERT Capsule", 16th AIAA DLR DGLR International Space Planes and Hypersonic Systems and Technologies Conference, Bremen, 2009

${ }^{5}$ J. M. Longo, J. Turner H. Weihs, "SHEFEX II - Aerodynamic Re-Entry Controlled Sharp Edge Flight Experiment", 6th European Symposium on Aerothermodynamics for Space Vehicles , Versailles, 2008

${ }^{6}$ M. Sippel, A. van Foreest, "Latest Progress in Research on the SpaceLiner High-Speed Passenger Transportation Concept", IAC-07-D2.7.07, International Astronautical Congress, Hyderabad, 2007

${ }^{7}$ J. Marschall, D. A. Pejakovic, W. G. Fahrenholtz, G. E. Hilmas, S. Zhu, J. Ridge, D. G. Fletcher, C. O. Asma, J. Thömel, "Oxidation of $\mathrm{ZrB}_{2}-\mathrm{SiC}$ Ultrahigh-Temperature Ceramic Composites in Dissociated Air", Journal of Thermophysics and Heat Transfer, Vol. 23, No. 2, April-June 2009

${ }^{8}$ A. van Foreest, M. Sippel, A. Gülhan, B. Esser, B. A. C. Ambrosius, K. Sudmeijer, "Transpiration Cooling Using Liquid Water", Journal of Thermophysics and Heat Transfer, Vol. 23, No. 4, October-December 2009

${ }^{9}$ M. Kuhn, H. Hald: "Application of Transpiration Cooling for Hot Structures", Notes on Numerical Fluid Mechanics and Multidisciplinary Design, Vol. 98, Springer-Verlag, Berlin Heidelberg, 2008, pp. 82-103

${ }^{10}$ B. Esser, A. Gülhan, M. Kuhn, "Thermal qualification of transpiration cooling for atmospheric entry". $1^{s t}$ CEAS European Air and Space Conference, Berlin, 2007

${ }^{11}$ N. Gascoin, G. Fau, P. Gillard, M. Kuhn, M. Bouchez, J. Steelant, "Benchmark of Experimental Determination Methods of Gas Permeabilities", $17^{\text {th }}$ International Space Planes and Hypersonic Systems and Technologies Conference, San Francisco, 2011

${ }^{12}$ A. Gülhan, B. Esser, "Arc-Heated Facilities as a Tool to Study Aerothermodynamic Problems of Reentry Vehicles", Progress in Astronautics and Aeronautics, Vol. 198, AIAA, 2002, pp. 375-403

${ }^{13}$ A. Gülhan, B. Esser, "A Study on Heat Flux Measurements in High Enthalpy Flows", $35^{\text {th }}$ AIAA Thermophysics Conference, Anaheim, CA, 2001. 